\author{
Universidade de São Paulo \\ Faculdade de Saúde Pública \\ Programa de Pós-Graduação em Saúde Pública
}

\title{
Impacto da doença articular referida na funcionalidade de idosos
}

\author{
Francine Leite
}

Tese apresentada ao Programa de Pós

Graduação em Saúde Pública para obtenção do título de Doutor em Ciências.

Área de Concentração: Epidemiologia

Orientadora: Prof. ${ }^{a}$ Dr. ${ }^{\underline{a}}$ Yeda A. O. Duarte 


\title{
Impacto da doença articular referida na funcionalidade de idosos
}

\author{
Francine Leite
}

Tese apresentada ao Programa de Pós Graduação em Saúde Pública para obtenção do título de Doutor em Ciências.

Área de Concentração: Epidemiologia

Orientadora: Prof. ${ }^{a}$ Dr. ${ }^{\underline{a}}$ Yeda A. O. Duarte 
É expressamente proibida a comercialização deste documento, tanto na sua forma impressa como eletrônica. Sua reprodução total ou parcial é permitida exclusivamente para fins acadêmicos e científicos, desde que na reprodução figure a identificação da autora, título, instituição e ano da tese. 


\section{DEDICATÓRIA}

Aos idosos e seus familiares que participaram do $S \mathcal{A B E}$, permitindo a realização deste estudo.

Aos meus pais, Joaquim e Cída, que proporcionaram e proporcionam a estrutura da estrada para que eu caminhasse até aqui. 


\section{AGRADECIMENTOS}

A Deus, por me dar força nos momentos de fraqueza.

À minha orientadora, pela paciência, ensinamentos e pela persistência.

Ao doutor Sérgio Marcio Pacheco Paschoal, pelos apontamentos e considerações para o aprimoramento da tese.

À professora doutora Ana Carolina Basso Schmitt pela leitura, discussão e reflexões sobre a tese, proporcionando um melhor olhar fisioterapêutico.

À professora doutora Elizabeth Alves Gonçalves Ferreira pela leitura e considerações e apontamentos para a melhoria desta tese.

Ao professor doutor Luiz Eugênio Garcez pela leitura, disponibilidade e comentários feitos neste trabalho, desde a etapa da qualificação.

Ao professor Dr. Jair Licio Ferreira Santos, por toda ajuda e pela sempre disponibilidade em me socorrer durante as análises estatísticas.

À professora doutora Fabíola Bof de Andrade, por todo auxílio para o desenvolvimento desta tese, pelas leituras, pelas reuniões, pela paciência e pelas discussões e pelas considerações até o final. O meu muito e sempre obrigada!

À professora Maria Lucia Lebrão, pela oportunidade em fazer parte do SABE.

À fisioterapeuta $\mathrm{Dr}^{\mathrm{a}}$. Ângela Bushatsky pelas considerações, sugestões e discussões sobre a tese.

Aos idosos e seus familiares, por participarem do SABE.

À minha família: aos meus pais, Joaquim e Cida, por toda a educação e por todos os sacrifícios que permitiram essa minha conquista. Aos meus irmãos, Fernanda e Flávio, pela paciência, pelas ajudas indiretas e, por mesmo longe, estarmos sempre juntos!

Ao Fredy Galvis Ovallos, meu amigo, parceiro e companheiro, obrigada por tudo: da ajuda nas disciplinas obrigatórias ao final desta tese. Seu apoio, incentivo e dedicação me deram forças e foram fundamentais para chegar até aqui.

Ao Instituto de Estudos de Saúde Suplementar por ter permitido que eu fizesse o doutorado, flexibilizando os horários de trabalho. Um obrigada especial para os que permitiram isso ou me cobriram nos momentos de ausência: José Cechin, Carina Burri Martins, Luiz Augusto Carneiro, Andreia Ferreira, Marcos Novais, Amanda Reis e Greice Mansini. 
Aos professores da disciplina de graduação HEP141 quando fui aluna PAE e por tudo que aprendi durante o estágio: Prof. ${ }^{a}{ }^{\text {D }}$ Dr. $^{\text {a. }}$ Márcia Furquim, Prof. ${ }^{a}$.

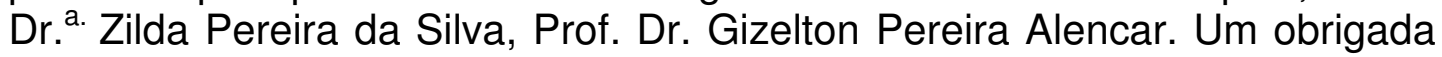
especial à Prof. ${ }^{a}$ Dr. ${ }^{a}$. Eunice Aparecida Bianchi Galati, que além do estágio PAE pude conviver um pouco mais, aprender muito mais e pelas discussões que muito contribuíram para minha formação.

Às pessoas envolvidas com o SABE: Nazaré, Ângela, Márcia e Fernão - por estarem sempre disponíveis nos momentos que precisei. Aos entrevistadores, digitadores e todas as pessoas que trabalharam para que os idosos fossem entrevistados e que essas informações se transformassem em um banco de dados.

Aos funcionários do departamento de Epidemiologia e do Serviço de PósGraduação por toda a assistência.

Aos meus sempre mestres: Marina Ferreira, por desenvolver meu senso crítico, ao Prof. Dr. Jaime de Oliveira Gomes por me "corromper" para a Saúde Pública e por ter aguçado às dúvidas e questionamentos, à Prof. ${ }^{a}$. Dr. ${ }^{2}$ Maria da Conceição Pereira Saraiva por ter me ensinado as técnicas e a como encontrar as respostas das dúvidas e questionamentos.

Aos companheiros da pós-graduação, Carlos Lima Rodrigues, Jorge Bento, Henrique Salmazo e Doralice Teixeira pelos momentos de desespero, ajuda, compreensão e descontração!

Aos meus familiares e amigos, de longe e de perto, de décadas ou de meses, que sempre me incentivaram e compreenderam minhas ausências, que sempre tiveram palavras de apoio e que compreenderam meus momentos de mau-humor e estresse. 
LEITE, F. O impacto da doença articular referida na funcionalidade de idosos. [Tese de doutorado]. São Paulo: Faculdade de Saúde Pública da Universidade de São Paulo, 2013.

\section{RESUMO}

Introdução: As doenças articulares, frequentes entre idosos, estão relacionadas ao comprometimento funcional. Objetivo: Avaliar o impacto da doença articular referida no comprometimento funcional em idosos residentes na área urbana do município de São Paulo no período entre 2000 e 2006. Métodos: Este trabalho é parte do Estudo Saúde, Bem-Estar Envelhecimento (SABE). Foram estudados 336 idosos residentes na zona urbana do município de São de Paulo, entrevistados em 2000 e em 2006, representando 162.913 idosos do município. A variável dependente do estudo foi o desenvolvimento de comprometimento funcional e a variável independente foi a doença articular referida entre 2000 e 2006, adicionalmente com as covariáveis sociodemográficas e de saúde. A relação entre as variáveis foi analisada pelo teste de Rao Scot, seguida pelo modelo de regressão logística multinomial e os cálculos do risco atribuível. Considerou-se nível de significância de $5 \%$ e intervalos de confiança de 95\%. Resultados: No período de 6 anos, observou-se uma incidência de $47,8 \%$ de dificuldade de mobilidade e $7,3 \%$ de desempenhar atividades de vida diária (AVDs). A doença articular não foi associada ao comprometimento funcional. O sexo feminino foi associado à dificuldade de mobilidade e a idade avançada (70 anos ou mais) e a baixa escolaridade 
(até 3 anos de estudo) foram associados à dificuldade de desempenho das AVDs. Na população, $9,2 \%$ do comprometimento funcional foi atribuído à doença articular. Ainda, entre os idosos que relataram a doença articular, $30,1 \%$ do comprometimento funcional foi atribuído a ela. Conclusões: Apesar do impacto da doença articular no comprometimento funcional da população ser representativo, a doença articular não foi associada à incidência de comprometimento funcional nesse estudo.

Descritores: Limitação da mobilidade, Atividades cotidianas, Idosos, Doença Articular 
LEITE, F. The impact of referred joint disease to functionality in elderly. [Tese de doutorado]. São Paulo: Faculdade de Saúde Pública da Universidade de São Paulo, 2013.

\section{ABSTRACT}

Introduction: The joint disease, common among the elderly, are related to functional impairment. Objective: To evaluate the impact of referred joint disease to functional impairment among elderly living in the urban area of São Paulo between 2000 and 2006. Methods: This study is part of Health Well Being Aging Study (SABE study). We studied 336 elderly residents in the urban area of São Paulo, who were interviewed in 2000 and 2006, representing 162,913 seniors. The dependent variable was functional impairment and the independent variable was joint disease development between 2000 and 2006, in addition to the sociodemographic and health covariates. The association between variables was analyzed using Rao Scot test, followed by multinomial logistic regression model and attributable risk calculations. It was considered a significance level of $5 \%$ and confidence interval of $95 \%$. Results: During the 6-year-period, the incidence of mobility impairment was $47.8 \%$ and incidence of activities of daily living (ADLs) disability was $7.3 \%$. The joint disease was not associated with functional impairment. Being female was associated with difficulty in mobility difficulties and advanced age (up to 70 years old) and lower education (up to 3 years) were associated with difficulty in performing ADLs. Among population, 9.2\% 
of functional impairment was attributed to joint disease. Still, among the elderly who reported joint disease, $30.1 \%$ of functional impairment was attributed to it. Conclusions: despite the expressive impact of joint disease on functional impairment, it was not associated with incidence of disability in this study.

Descriptors: Mobility, Limitation Activities of daily living, Elderly, Join Disease 


\section{SUMÁRIO}

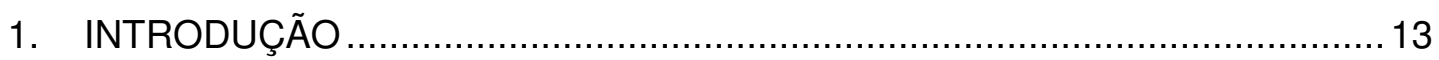

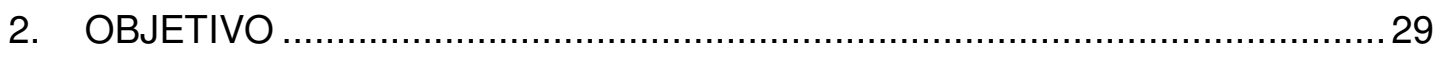

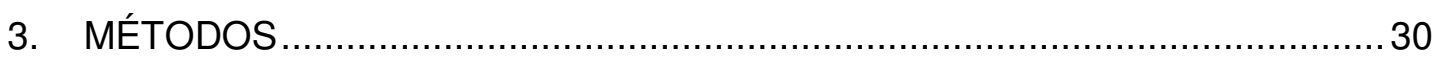

3.1. Localização do Estudo e População-alvo .................................................... 30

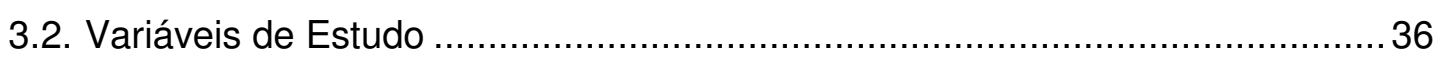

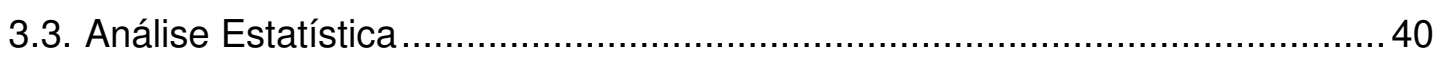

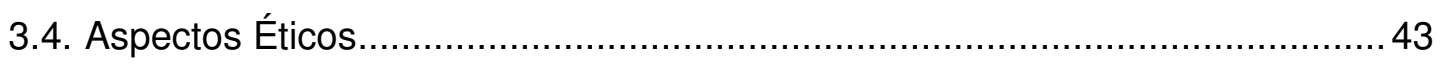

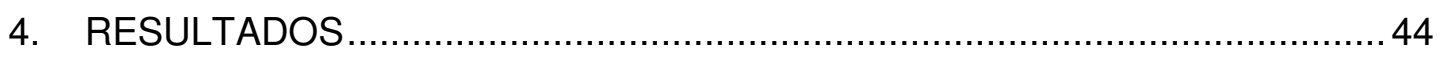

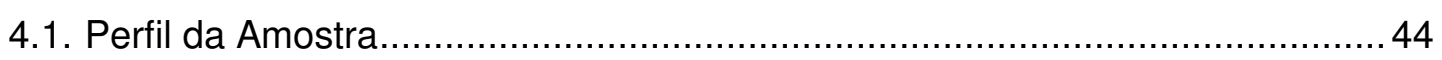

4.2. Análise Descritiva da Incidência do Comprometimento Funcional...................46

4.3. Análise Descritiva e Analítica da Incidência do Comprometimento das Ações de Mobilidade em Relação à Doença Articular ...................................................... 49

4.4. Fatores Associados aos Níveis de Comprometimento Funcional ...................59

4.5. Risco de Comprometimento Funcional Atribuível à Doença Articular ...............61

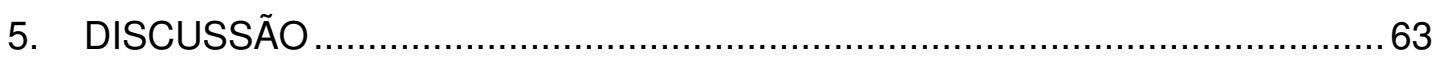

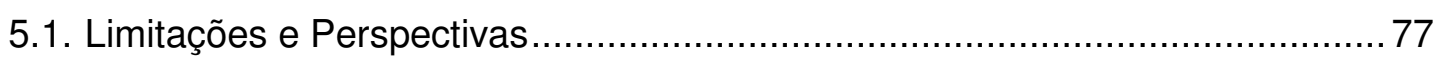

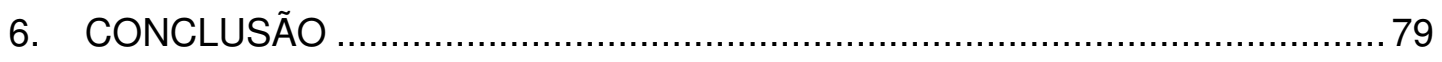

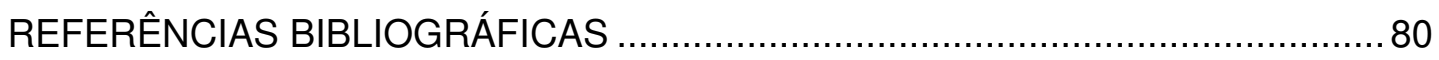

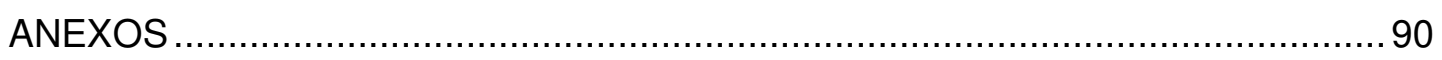

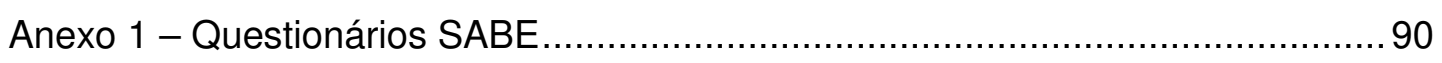

Anexo 2 - Pareceres do Comitê de Ética em Pesquisa....................................... 91

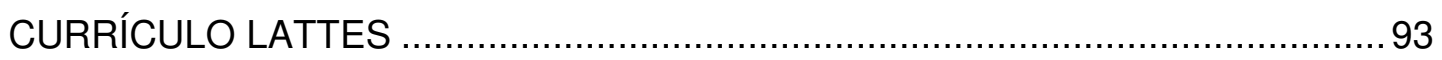

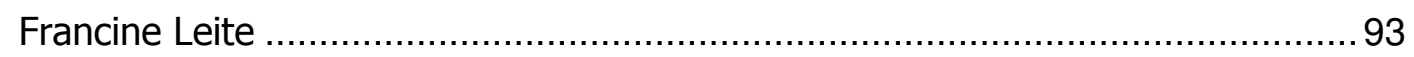

Yeda Aparecida de Oliveira Duarte .......................................................... 94 


\section{LISTA DE SIGLAS E ABREVIATURAS}

\begin{tabular}{|c|c|}
\hline ABVD & Atividades básicas de vida diária \\
\hline AIVD & Atividades instrumentais de vida diária \\
\hline AVE & Acidente vascular encefálico \\
\hline CIF & Classificação Internacional de Funcionalidade \\
\hline DANT & Doenças e agravos não transmissíveis \\
\hline DPOC & Doença pulmonar obstrutiva crônica \\
\hline FIV & Fator de inflação de variância \\
\hline IBGE & Instituto Brasileiro de Geografia e Estatística \\
\hline MS & Ministério da Saúde \\
\hline OMS & Organização Mundial da Saúde \\
\hline OPAS & Organização Pan-Americana da Saúde \\
\hline PNAD & Pesquisa Nacional por Amostra de Domicílios \\
\hline RA & Risco atribuível \\
\hline $\mathrm{RAP}_{\mathrm{pop}}$ & Risco atribuível proporcional populacional \\
\hline SABE & Saúde, Bem-Estar e Envelhecimento \\
\hline SBR & Sociedade Brasileira de Reumatologia \\
\hline WHO & World Health Organization \\
\hline
\end{tabular}




\section{LISTA DE TABELAS}

Tabela 1: Perfil da amostra do estudo SABE em 2000, conforme participação na amostra selecionada para o estudo, segundo variáveis sociodemográficas e de saúde selcionadas. São Paulo, 2000-2006. 45

Tabela 2: Distribuição (\%) da incidência do comprometimento funcional entre os idosos segundo o relato de doença articular entre 2000 e 2006. São Paulo, 2000 e 2006. 46

Tabela 3: Distribuição (\%) da incidência do comprometimento funcional entre os idosos segundo as variáveis sociodemográficas e de saúde em 2000. São Paulo, 2000 e 2006 .... 48

Tabela 4: Distribuição (\%) e odds ratio da doença articular referida entre 2000 e 2006 segundo a incidência de dificuldade em ações de mobilidade selecionadas. São Paulo, 2000 e 2006. 50

Tabela 5: Distribuição (\%) e odds ratio da doença articular referida entre 2000 e 2006 segundo a incidência de dificuldade em ações de mobilidade selecionadas entre os homens. São Paulo, 2000 e 2006. 52

Tabela 6: Distribuição (\%) e odds ratio da doença articular referida entre 2000 e 2006 segundo a incidência de dificuldade em ações de mobilidade selecionadas entre as mulheres. São Paulo, 2000 e 2006. 54

Tabela 7: Distribuição (\%) e odds ratio da doença articular referida entre 2000 e 2006 segundo a incidência de dificuldade em ações de mobilidade selecionadas na faixa etária entre 60 e 69 anos. São Paulo, 2000 e 2006.. 56

Tabela 8: Distribuição (\%) e odds ratio da doença articular referida entre 2000 e 2006 segundo a incidência de dificuldade em ações de mobilidade selecionadas na faixa etária a partir de 70 anos. São Paulo, 2000 e 2006.. 58

Tabela 9: Modelo de regressão logística multinomial para incidência de dificuldade na mobilidade segundo a doença articular referida em 2000 e em 2006. São Paulo, 2000 e 2006. 59

Tabela 10: Modelo de regressão logística multinomial para incidência de dificuldade nas atividades de vida diária segundo a doença articular referida em 2000 e em 2006. São Paulo, 2000 e 2006. 60

Tabela 11: Incidência da limitação funcional e doença articular, segundo ao ano de relato da doença articular. 


\section{INTRODUÇÃO}

O envelhecimento é um processo natural e individual caracterizado pela diminuição progressiva das respostas adaptativas do corpo frente ao meio ambiente (OPAS, 2005). Às alterações consideradas fisiológicas e associadas com o avançar da idade denomina-se "senescência" e, quando acompanhadas por processos patológicos, "senilidade" (MS, 2007).

Independente da presença de doenças, é importante que essa fase da vida seja vivida com boa qualidade de vida (OMS, 2003). Entende-se por qualidade de vida "a percepção de bem-estar de uma pessoa, que deriva de sua avaliação do quanto realizou daquilo que idealiza como importante para uma boa vida e de seu grau de satisfação com o que foi possível concretizar até aquele momento" (PASCHOAL, 2004), sendo a capacidade funcional/autonomia uma de suas dimensões.

Alguns fatores têm permitido que mais pessoas envelheçam, como a redução da taxa de mortalidade e a melhoria das condições sociais (BRITO, 2008; CARVALHO e RODRIGUEZ-WONG, 2008; MENDES, 2012).

Outro fator importante que deve ser considerado é o avanço técnicocientífico, que permite paulatinamente a realização de diagnósticos mais precoces e tratamentos mais avançados das condições crônicas (SMITH, HEFFLER E FREELAND, 2000). Além disso, ressalta-se a velocidade da transição demográfica, que vem ocorrendo na América Latina (SAAD, MILLER e MARTINEZ, 2009). 
Os países desenvolvidos ${ }^{1}$ apresentam uma alta proporção de pessoas idosas, como, por exemplo, os Estados Unidos, com 16,5\%, a França, com $21,4 \%$, e a Suécia, com $22,7 \%$. O processo para duplicar a população de idosos de $7 \%$ para $14 \%$ aconteceu em períodos relativamente longos: a França em 115 anos, a Suécia, em 85 anos e os Estados Unidos, em 69 anos - para efeitos de comparação, considerando essa mesma faixa etária, no Brasil, projeta-se que esse processo levará cerca de 21 anos (NATIONAL INSTITUTE OF AGING, 2007).

Entretanto, essa velocidade é ainda maior ao considerarmos a população idosa brasileira com 60 anos ou mais. De acordo com o Censo de 2010 a população idosa brasileira representava 10,8\% (IBGE, 2011) e, estima-se que em 2030 e 2050 representará 18,7\% e 29,8\%, respectivamente (IBGE, 2010).

Essa transição demográfica acelerada também é acompanhada por mudanças no perfil epidemiológico, em especial pelo aumento na prevalência de condições crônicas (PAES-SOUSA, 2002; SCHRAMM et al., 2004; MENDES, 2012). As condições crônicas são aquelas que requerem tratamento contínuo por um período de vários anos, incluindo algumas categorias como as doenças transmissíveis (HIV/AIDS, tuberculose), as não transmissíveis (doenças cardiovasculares e osteomusculares, entre outras) e incapacidades estruturais (amputações, cegueira e transtornos das articulações) (OMS, 2003).

\footnotetext{
${ }^{1}$ Esses países consideram idosos os indivíduos com 65 anos ou mais.
} 
Essas condições são multifatoriais e relacionadas tanto a fatores de risco não modificáveis (idade, sexo e raça) quanto aos fatores modificáveis (tabagismo, inatividade física e hábitos alimentares inadequados), e estão associadas a uma maior utilização dos serviços de saúde (MALTA et al., 2006) e à idades mais avançadas (ANDERSON e HORVARTH, 2004).

A associação entre condições crônicas e idade poderia ser explicada, em parte, pelo aumento da sobrevida das pessoas com doenças antes fatais e agora transformadas em crônicas, o que está relacionado ao avanço técnico-científico (ANDERSON e HORVARTH, 2004).

Dentre as múltiplas consequências das condições crônicas, destacase o comprometimento da funcionalidade (FRIED et. al., 2000; ROSA et al., 2003; ALVES et al., 2007), o que varia conforme a doença ou o agravo considerado. Entre as condições que comprometem a funcionalidade destacam-se as musculoesqueléticas, as sensoriais, as cardiovasculares e as neurológicas, entre outras (FRIED et al., 1999; FREEDMAN et al., 2000; FRIED et. al., 2000; ROSA et al., 2003; KATTAINEN et al., 2004; ALVES et al., 2007; KLIJS et al., 2011; DUBA et al., 2012; PALAZZO et al., 2012).

Entre as doenças crônicas, o grupo das doenças articulares representa uma elevada carga tanto para o indivíduo quanto para a sociedade, que embora não esteja entre as principais causas de morte demanda o sistema de saúde devido sua associação com o progressivo comprometimento funcional (WHO, 2003; BINDAWAS et al., 2011; KWOK et al., 2011). 
A incapacidade é considerada uma das principais adversidades relacionadas às doenças crônicas e às alterações biológicas associadas ao envelhecimento, pois compromete a manutenção da vida de forma independente, uma vez que limita de forma mais ou menos grave a mobilidade e o desempenho das atividades cotidianas, desde as que proporcionam uma vida comunitária independente até as relacionadas ao cuidado pessoal (FRIED et al., 1999; FREEDMAN et al., 2000; FRIED et. al., 2000; ROSA et al., 2003; KATTAINEN et al., 2004; ALVES et al., 2007; KLIJS et al., 2011; DUBA et al., 2012).

A definição de incapacidade é muito abrangente, inclui conceitos de função do corpo, participação na sociedade, atividades e condição de saúde (OMS, 2003). Alguns autores definem a incapacidade como a dificuldade ou impossibilidade para desempenhar determinados movimentos ou atividades específicas que são fundamentais para que as pessoas possam ser independentes para o autocuidado ou para manter uma vida comunitária independente (ROSA et al., 2003; FRIED et al., 2004).

VERBRUGGE e JETTE (1994) conceituam incapacidade como um processo sequencial unidirecional, que se inicia a partir de uma alteração do organismo, que gera uma disfunção e que, em conjunto com fatores ambientais ou sociais, aceleram ou retardam o comprometimento funcional, denominado como processo de incapacitação ("Disablement Process" tradução livre). Esse processo descreve a trajetória da incapacidade ao longo do tempo, a partir de uma condição patológica e suas consequências funcionais incluindo os fatores que afetam seus padrões. Adicionalmente a 
esse conceito, VERBRUGGE e JETTE (1994) diferenciaram a incapacidade de limitação funcional. Segundo esses autores, a limitação funcional relaciona-se a dificuldade de execução de uma ação exigida sem contextualização, enquanto a incapacidade envolve uma atividade dentro de um contexto social (VERBRUGGE e JETTE, 1994).

Essa definição pode ser exemplificada a partir do caso de uma mulher de 75 anos com diminuição da amplitude de movimento da articulação glenoumeral (ombro). Essa restrição de movimento não permite que essa idosa consiga erguer o braço acima do ombro (limitação funcional), o que restringe, entre outras limitações, a sua capacidade de lavar ou pentear os cabelos (incapacidade). O comprometimento funcional, assim, pode ser observado tanto pela limitação funcional quanto pela incapacidade.

Posteriormente ao modelo de VERBRUGGE e JETTE (1994) e, em evolução ao mesmo, a Organização Mundial da Saúde (OMS) desenvolveu um modelo a partir de diferentes construtos e domínios envolvidos na funcionalidade e suas interações. Esses domínios envolvem as atividades que interagem com as condições de saúde, com as funções e estruturas corporais, a participação na sociedade e a relação com os fatores ambientais e individuais (OMS, 2003). Essa estruturação foi desenvolvida para fins de classificação e ampliação das questões relacionadas à saúde para além da doença. Surgiu assim a Classificação Internacional de Funcionalidade (CIF), que não é descrita com construtos e domínios condicionantes ou unidirecionais. Isso permite que sua definição seja 
associada ou não a uma condição patológica e dependente da interação de todos esses fatores descritos (OMS, 2003).

Para o desenvolvimento desse trabalho adotou-se o modelo de VERBRUGGE e JETTE por se adequar à hipótese de que a doença pode levar ao comprometimento funcional.

A dificuldade em desempenhar ações ou atividades relacionadas ou não a um contexto social ou de autocuidado foi denominado como "comprometimento funcional". Como "dificuldade de mobilidade" define-se a dificuldade ou impossibilidade em realizar ações não específicas ("limitação") e "dificuldade em desempenhar as atividades de vida diária (AVDs)" à dificuldade ou impossibilidade em desempenhar atividades cotidianas ou de autocuidado que permitem uma vida comunitária independente (“incapacidade”, segundo VERBRUGGE e JETTE, 1994).

O comprometimento funcional pode se instalar de duas formas: a primeira, denominada "catastrófica", que ocorre de forma abrupta em decorrência de algum evento específico (acidente vascular encefálico ou acidente etc.) e a segunda que ocorre de forma progressiva, com início pouco perceptível para o indivíduo acometido e evolução progressiva e gradativa ao longo de tempo (FERRUCCI et al., 1996; COVINSKY, 2006).

Estima-se que metade das dificuldades em desempenhar as AVDs ocorra de forma progressiva, acometendo principalmente os idosos mais longevos ( $\geq 85$ anos), e a outra metade esteja relacionada a algum evento catastrófico, mais prevalente entre os idosos mais jovens (69 e 75 anos) (FERRUCCl et al., 1996). Isso ocorre pois as doenças crônicas podem agir 
diferentemente em cada faixa etária. Entre os idosos mais jovens o efeito das dificuldades é contrabalanceado por estratégias de compensação e quando esses mecanismos falham, a incapacidade grave ocorre. Nos idosos mais longevos esse mecanismo de compensação é menos eficiente em decorrência do próprio processo de envelhecimento (FERRUCCl et al., 1996).

Quando o curso da incapacitação é progressivo, o comprometimento funcional se inicia com dificuldades de mobilidade, que evoluem para a dificuldade no desempenho das AVDs, podendo progredir para perda de independência (HARRIS et al., 1989; GILL et al., 1998; FRIED et al., 2000). Ainda, de acordo com DUNLOP et al. (1997), o comprometimento funcional progressivo se inicia, geralmente, com a dificuldade da caminhada, seguida da dificuldade de banhar-se, depois de se transferir, evoluindo para a dificuldade em se vestir, utilizar o banheiro e, por último, se alimentar (DUNLOP et al., 1997).

A prevalência do comprometimento funcional em idosos é elevada: GRACIANI et al. (2004) observaram que $72,9 \%$ do idosos reportaram algum comprometimento, sendo que $19,1 \%$ reportaram alguma dificuldade para banhar ou vestir, outros $40,1 \%$ reportaram dificuldade em tarefas de contexto social e $51,6 \%$ relataram dificuldade de mobilidade.

PALACIOS-CEÑA et al. (2012) observaram maior prevalência de comprometimento funcional entre as mulheres. Nas atividades de autocuidado a prevalência entre as mulheres variou entre $12,1 \%$ e $15,8 \%$ e entre os homens variou de $7,1 \%$ a $10,6 \%$. Com relação às tarefas que 
envolvem o contexto social (caminhar ao redor da casa, preparar refeições, gerenciar finanças, usar telefone e tomar medicação) a prevalência variou entre $22,7 \%$ e $29,6 \%$ entre as mulheres e entre $19,3 \%$ e $26,3 \%$ nos homens. Em relação dificuldade de mobilidade (caminhar por $1 \mathrm{~h}$ e subir 10 degraus) a prevalência também foi maior entre as mulheres $(25,0 \%$ e $32,6 \%)$ do que entre os homens $(14,8 \%$ e $19,8 \%)$.

Em estudo de LIU et al. (2009) a prevalência de comprometimento funcional foi de $8,1 \%$. No Brasil, PARAHYBA e SIMÕES (2006) observaram que, em média, 26,6\% dos idosos relataram dificuldade de mobilidade, principalmente em idosos mais longevos ( $\geq 80$ anos) $(48,4 \%)$.

Observa-se nesses estudos maior prevalência de dificuldade de mobilidade do que de desempenho nas AVDs, fato que pode estar relacionado com a dinâmica do processo de incapacidade ocorrer de forma progressiva e também por sofrer influência da mortalidade, dada sua associação com a incapacidade (HARRIS et al., 1989; SCOTT et al., 1997; MAJER et al., 2011).

Poucos são os estudos de incidência de comprometimento funcional. BALZI et al. (2010) estimaram incidência de comprometimento funcional de 8,5\% em um período de 3 anos e nesse mesmo período, aqueles que apresentaram algum comprometimento no início do seguimento, 10,8\% pioraram de condição (comprometimento de um maior número de tarefas). Para um período de 2 anos, DUNLOP et al (2002) observou em idosos a partir de 70 anos de idade uma incidência de comprometimento funcional entre $0,6 \%$ (alimentar-se) e 5,4\% (banhar-se), dependendo da tarefa 
estudada. Adicionalmente, SONG et al. (2006) observou uma incidência de $7,2 \%$ em um seguimento de idosos ( $\geq 65$ anos) por 7 anos. CHAUDHRY et al. (2010) observaram em um período de 5 anos incidência de $15 \%$ de dificuldade em desempenhar as AVDs e de $30 \%$ de dificuldade de mobilidade, para essa mesma faixa etária.

O comprometimento funcional tem sido associado à mortalidade (GURALNIK et al., 1996), à menor expectativa de vida (CAMARGOS et al., 2005), hospitalização (GILL et al., 2004), institucionalização (WOO et al., 2000), com consequente impacto negativo na qualidade de vida dos idosos e seus familiares, além de gerar um aumento da procura por assistência à saúde (GURALNIK et al., 1996) e, assim, maior proporção dos gastos na saúde (STANTON e RUTHERFORD, 2005).

O comprometimento funcional também está associado aos fatores sociodemográficos e às condições de saúde. A idade mais avançada, ser do sexo feminino, não ter companheiro/a e possuir baixo nível de escolaridade são os fatores sociodemográficos associados com estes desfechos (KOUKOULI et al., 2002; ROSA et al., 2003; VON STRAUSS et al., 2003; DUBA et al., 2012; IDLAND et al., 2013).

A diferença de comprometimento funcional entre os sexos pode ser decorrente dos padrões de acometimento das doenças crônicas e das condições fisiológicas - as doenças que afetam as mulheres com maior frequência podem gerar maior perda de massa muscular e serem menos letais, no entanto, com menor recuperação da funcionalidade (FERRUCCl et al., 1996; OMAN et al., 1999; ALEXANDRE et al., 2012). Assim, enquanto as 
mulheres, ao longo da vida, se incapacitam lenta e progressivamente, os homens levam mais tempo para apresentar comprometimento funcional. Ainda em relação aos homens, outro fato que deve ser considerado é que os homens podem relatar menos comprometimento funcional do que as mulheres (FERRUCCI et al., 1996), explicando assim, a diferença de acometimento entre os sexos.

Quanto à idade, o fato do comprometimento funcional acometer principalmente os idosos longevos poderia ser explicado pela perda natural de adaptação do organismo do idoso (FERRUCCl et al., 1996) e também por uma maior sobrevida desse grupo vivendo com comprometimento funcional e comorbidades.

O baixo nível de escolaridade está diretamente relacionado ao pior nível socioeconômico, e consequentemente ao menor acesso aos serviços de saúde e piores condições de vida e saúde, fatores associados à maior predisposição a doenças e agravos e, posteriormente à dificuldade em desempenhar funções (HARRIS et al., 1989).

Quanto aos fatores relacionados à saúde e aos hábitos de vida ressaltam-se como associados ao comprometimento funcional o consumo alimentar deficiente (DUBA et al., 2012) e a inatividade física (DEN OUDEN et al., 2012). Além desses, destacam-se os déficits sensoriais (audição e visão) (DEN OUDEN et al., 2012;), o declínio cognitivo (SAUVAGET et al., 2002; ), assim como o relato de pior estado de saúde (SOUSA et al., 2009; LIN et al., 2010) e algumas doenças crônicas (DUNLOP et al., 2002; LING et 
al., 2006; COVINSKY et al., 2008; SOUSA et al., 2009; LIN et al., 2010; DUBA et al., 2012).

Estudos têm demonstrado que as doenças crônicas apresentam uma forte associação com o comprometimento funcional do idoso (DUNLOP et al., 2002; KLIJS et al., 2011; COVINSKY et al., 2008; LIN et al., 2010). Entre estas, a doença articular é considerada uma das mais limitadoras e incapacitantes (DUNLOP et al., 2002; FISHER et al., 2004; SONG et al., 2006; COVINSKY et al., 2008; SOUSA et al., 2009).

As doenças articulares ou artropatias são doenças que atingem predominantemente as articulações periféricas (OMS, 1995). Segundo a Classificação Internacional de Doenças em sua décima versão (CID-10), o grupo de artroses ou osteoartrite (M15-M19) é definido como "O termo osteoartrite é utilizado como sinônimo de artrose ou osteoartrose. O termo primário tem sido usado com seu significado usual em clínica quando não se identifica a afecção subjacente ou determinante".

Além dessa classificação consolidada, STEDMAN (2003) define "artrite" como um estado caracterizado por inflamação das articulações e "reumatismo" como um termo indefinido, aplicado a diversas condições caracterizadas por dor ou outros sintomas de origem articular.

Assim, de forma genérica, em inquéritos populacionais, as artropatias crônicas são denominadas como "artrite", "artrose", "osteoartrose", "osteoartrite" e "reumatismo". Em inquéritos realizados, principalmente nos Estados Unidos, o termo usado é artrite ("arthritis") (GUCCIONE et al., 1990; MARCH e BAGGA, 2004; NISHIMURA et. al, 
2011; PELÁEZ-BALLESTAS et. al, 2011; HORVATH et. al, 2011; PUEYO et. al, 2012; BIELAK et al., 2012; SAMPER-TERNENT et. al, 2012).

Essas denominações geralmente podem incluir outras condições, tais como artrite reumatóide, doença vertebral e outras artropatias. Apesar desse conjunto diversificado de alterações articulares, reconhece-se como condição mais prevalente entre os idosos a osteoartrose (OA) (FELSON e NEVITT, 2004; McDONOUGH e JETTE, 2010; ZHANG e JORDAN, 2010).

Entre as doenças articulares, a osteoartrose é considerada uma das doenças mais incapacitantes nesse grupo das doenças articulares (GUCCIONE et al., 1994). Essa doença compromete as articulações e/ou estruturas adjacentes como a sinóvia, as cartilagens articulares, as bursas, entre outras (CHOPRA e ABDEL-NASSER, 2008).

Adicionalmente, STEDMAN (2003) define a osteoartrose como uma artrite caracterizada pela erosão da cartilagem articular que se torna amolecida e desgastada, com ossificação das cartilagens articulares e crescimento de osteófitos marginais. Ainda, define que essas alterações resultam em dor e perda de função e que afeta principalmente as articulações de sustentação de peso e que é mais comum em idosos.

De acordo com a Sociedade Brasileira de Reumatologia, a osteoartrose é uma doença crônica caracterizada pela degeneração articular que ocorre por uma insuficiência de cartilagem (SBR, 2003). Os sinais observados nessa doença são a diminuição do espaço intra-articular e a formação dos osteófitos e sua sintomatologia inclui crepitação, rigidez, 
diminuição da mobilidade e dor nas articulações envolvidas (HAMERMAN, 1995, MARCH e BAGGA, 2004, BOS et al., 2008; KOPEC et al. , 2007).

Devido às inúmeras condições que podem estar envolvidas no conjunto, conforme explicitado, para o desenvolvimento desse estudo $\circ$ acometimento crônico e degenerativo da articulação será denominado "doença articular".

Estudos populacionais detectaram prevalência entre 10,4\%, em coreanos idosos (CHO et al., 2011) e 77,4\% (SAMPER-TERNENT et. al, 2012) entre idosas hispânicas residentes nos Estados Unidos. Essa ampla diferença entre essas prevalências (GUCCIONE et al., 1990; RASCH et. al, 2003; MARCH e BAGGA, 2004; MACHADO et al., 2004; BUSIJA et. al, 2007; CHO et al., 2011; GUILLEMIN et al., 2011; NISHIMURA et. al, 2011; PELÁEZ-BALLESTAS et. al, 2011; HORVATH et. al, 2011; PUEYO et. al, 2012; BIELAK et al., 2012; SAMPER-TERNENT et. al, 2012) tem como motivo a classificação da doença. Enquanto alguns autores especificam a região anatômica acometida (CHO et al., 2011; GUILLEMIN et al., 2011), os demais não o fazem. Ainda, há estudos que utilizam critério radiológico para classificar a doença articular (CHO et al., 2011; GUILLEMIN et al., 2011; NISHIMURA et. al, 2011).

Essas elevadas prevalências podem agravar 0 quadro epidemiológico, pois se estima que $37,4 \%$ dos indivíduos com a doença articular, residentes nos Estados Unidos, desenvolverão algum tipo de comprometimento funcional até 2030 (HOOTMAN e HELMICK, 2006). 
Observa-se que há uma maior prevalência de comprometimento funcional entre idosos com doença articular - podendo variar entre 11,2\% e $37 \%$ - valores esses que podem chegar à metade quando analisado no grupo de idosos sem essa doença (AL SNIH et al., 2001; DUNLOP et al., 1997; DUNLOP et al., 2001; SONG et al., 2006; BALZI et al., 2010).

COVINSKY et al. (2008) e SONG et al. (2006) observaram que idosos com doença articular apresentam maior risco em desenvolver comprometimento funcional. Segundo ALVES et al. (2007), o risco de dependência do idoso com a doença articular pode ser $127 \%$ maior em relação àqueles sem doença. Ainda, ZHAO et al. (2009) estimam que a doença articular seja responsável por 35\% do comprometimento funcional.

A maior prevalência de comprometimento funcional entre idosos com doença articular pode estar relacionada às alterações fisiológicas que a doença provoca nas articulações, comprometendo assim a amplitude dos movimentos (COVINSKY, 2006).

Mais do que referir a doença ou tê-la diagnosticada, a presença de sintomatologias, como a queixa de dor ou rigidez articular, pode ser importante. Segundo ODDING et al. (1998), a osteoartrose de quadril ou joelho definida por critérios sintomatológicos (dor ou rigidez matinal) constitui um fator preditor de comprometimento funcional, o que não ocorreu quando usados critérios radiológicos. Esses resultados podem indicar que os sintomas podem ser mais perceptíveis do que as das alterações detectáveis nas articulações mediante o exame radiológico, isso porque as alterações provocadas nas partes moles não são detectáveis nesse tipo de exame. 
Assim, a rigidez e da dor articular, bem como a dificuldade em desempenhar alguns movimentos ou funções podem ser marcadores importantes para que se atue na prevenção de incapacidades.

Quando consideradas atividades específicas, COVINSKY et al. (2008) observaram que idosos que referiram doença articular apresentaram maior risco no desenvolvimento de dificuldade de mobilidade. Essas atividades são consideradas fortes preditores de risco para 0 desenvolvimento de dificuldade em desempenhar as atividades de vida diária (FRIED et al., 2000), entretanto no estudo de AL SNIH et al. (2010) essa associação não foi observada.

O impacto da doença na população também é relevante. SONG et al. (2006) observaram que cerca de 1 em cada 4 novos casos de incidência de dificuldade em desempenhar as AVDs foi atribuído à doença articular.

Apesar de existirem vários fatores relacionados ao comprometimento funcional (FELSON et al., 2000), a doença articular torna a pessoa vulnerável ao comprometimento funcional, podendo vir a desenvolvê-lo progressivamente (COVINSKY, 2006), dado à degeneração articular que ocorre lentamente (FERRUCCI et al., 2006), tornando-se necessário desenvolver uma atenção mais direcionada à população acometida pela doença. Isso porque este processo de comprometimento funcional é pouco evidente para os próprios idosos, seus familiares e para a maioria dos profissionais de saúde, não sendo oferecida a devida atenção aos seus sinais e sintomas. 
Dessa forma, o início de comprometimento funcional, principalmente a dificuldade de mobilidade, poderiam ser marcadores clínicos a serem utilizados na atenção à saúde para que se possa agir na prevenção ou minimização de comprometimentos funcionais decorrentes da doença articular.

Diante do exposto, é necessário conhecer melhor a associação da doença articular com o comprometimento funcional (McDONOUGH e JETTE, 2010), especialmente no tocante à dificuldade de mobilidade e de desempenhar as atividades de vida diária, em relação à doença articular. 


\section{OBJETIVO}

Avaliar o impacto da doença articular referida no comprometimento funcional de idosos residentes na área urbana do município de São Paulo no período entre 2000 e 2006.

\section{Objetivos específicos:}

- Estimar a incidência de comprometimento funcional em idosos em relação ao relato da doença articular referida no período entre 2000 e 2006;

- Descrever e analisar as atividades relacionadas à dificuldade de mobilidade com a doença articular referida;

- Avaliar a relação entre a doença articular referida e o comprometimento funcional e seus fatores associados;

- Estimar a proporção de comprometimento funcional entre os idosos, atribuível à doença articular. 


\section{MÉTODOS}

\subsection{Localização do Estudo e População-alvo}

Este trabalho é parte do estudo Saúde, Bem-Estar Envelhecimento (SABE), estudo longitudinal de múltiplas coortes desenvolvido desde o ano $2000 \mathrm{com}$ pessoas com idade igual e superior a 60 anos residentes na zona urbana do município de São Paulo. Em 2010 iniciou-se a terceira onda com a coorte de 2000 e a segunda coorte de idosos entre 60 e 64 anos (Coorte C10).

Inicialmente, o Estudo SABE foi desenvolvido em sete centros urbanos na América Latina e Caribe (Buenos Aires - Argentina, Bridgetown Barbados, São Paulo - Brasil, Santiago - Chile, Havana - Cuba, Cidade do México - México e Montevidéu - Uruguai) com o objetivo de traças o perfil das condições de vida e saúde das pessoas idosas residentes nessa região. Esse estudo foi desenvolvido pela Organização Pan-Americana de Saúde (OPAS) e no município de São Paulo o trabalho foi coordenado pelo Departamento de Epidemiologia da Faculdade de Saúde Pública da Universidade de São Paulo.

Em 2000, a amostra do município de São Paulo foi composta por 2.143 indivíduos, de ambos os sexos, com idade igual e superior a 60 anos (Coorte A00). Essa amostra foi representativa da população idosa residente na área urbana do município em 1996 (IBGE, 1996), que correspondeu a $8,1 \%$ dos 836.223 idosos. 
Esse tamanho de amostra foi definido, segundo SILVA (2003) a partir da definição do número mínimo de domicílios a serem sorteados (5882 domicílios) e pela fórmula [d=(1500*10/3)/0,85], sendo:

- 1500 o número mínimo de idosos para possibilitar as análises desejadas;

- 10/3 a razão referente a 3 idosos para cada 10 domicílios;

- $\quad 0,85$ a taxa de sucesso esperada para localização e realização das entrevistas nos domicílios sorteados.

O sorteio dos domicílios foi realizado pelo método de amostragem por conglomerados em dois estágios, com o critério de partilha proporcional ao tamanho. Para o primeiro estágio foi utilizado o cadastro permanente de 72 setores censitários da Pesquisa Nacional por Amostra de Domicílios (PNAD) de 1995 e calculado a fração de amostragem deste estágio por: $\mathrm{f1}=(72 * \mathrm{Di}) / \mathrm{D}$, sendo "f1" a fração de amostragem deste estágio, "Di" o número de cada setor e "D" o total de domicílios existentes no município de São Paulo. No segundo estágio foram calculados o número de domicílios a serem sorteados, definido por $\mathrm{f} 2=90 / \mathrm{Di}$, sendo aproximado para $90 \circ$ resultado do número de domicílios a serem sorteados em relação ao total de setores censitários, a partir da utilização dos endereços, segundo a PNAD de 1998 (SILVA, 2003).

A probabilidade de um domicílio pertencer à amostra sorteada foi definida por $f=f 1^{*} f 2$. Nos domicílios sorteados, foram identificados 1852 idosos elegíveis, dos quais 1568 concordaram em participar do estudo $(84,67 \%)$. 
Essa amostra foi ampliada para 2143 idosos para complementar o número de idosos com idade igual ou superior a 75 anos e do sexo masculino, em função da maior taxa de mortalidade desses dois grupos (SILVA, 2003). Essa complementação de amostra foi selecionada pela localização de moradias próximas aos setores selecionados ou, no máximo, dentro dos limites dos distritos dos setores sorteados (SILVA, 2003).

Para ajustar a distribuição da amostra à composição da população, foram calculados pesos para cada sexo e grupo etário. Além disso, foram calculados pesos para cada setor censitário para compensar probabilidades desiguais de sorteio do segundo estágio, devido à atualização das listas de endereço pela PNAD de 1998 (SILVA, 2003).

O questionário utilizado para a obtenção das informações do estudo SABE foi elaborado por um comitê regional, composto pelos principais pesquisadores de cada país participante e por especialistas em temas específicos da pesquisa. Esse instrumento foi composto por onze seções, que incluíram informações como: dados pessoais, avaliação cognitiva, estado de saúde, estado funcional, medicamentos, uso e acesso aos serviços, rede de apoio familiar e social, história laboral e fontes de ingresso, características da moradia, antropometria, flexibilidade e mobilidade.

As variáveis incluídas em cada seção foram:

- Seção A - Dados Pessoais: ano e país de nascimento; local de residência durante os primeiros quinze anos de vida; local de residência durante os últimos cinco anos de vida e, onde fosse aplicável, razões para a 
mudança de residência; história e estado marital; número de filhos; sobrevivência dos pais e, se não, a idade em que faleceram; escolaridade.

- Seção B - Avaliação Cognitiva: auto-avaliação da memória; avaliação da memória pelo teste mini-mental modificado e validado no Chile para realização do estudo. Para os que obtivessem escore igual ou inferior a 12 pontos, uma escala de desempenho funcional era administrada a um proxi-respondente (informante substituto) a partir da questão "é capaz de...".

- Seção C - Estado de saúde: auto-avaliação de saúde atual e comparativa ao ano anterior, bem como da saúde na infância; doenças referidas, considerando nove das doenças crônicas mais prevalentes na população idosa e incluindo seu tratamento; hábitos, condições sensoriais; saúde reprodutiva; saúde bucal; ocorrência de quedas; escala de avaliação de depressão geriátrica e mini screening nutricional.

- Seção D - Estado Funcional: avaliação do desempenho funcional e da ajuda recebida, quando necessário, nas atividades básicas e instrumentais da vida diária e identificação e caracterização dos cuidadores principais.

- Seção E - Medicamentos: terapêutica medicamentosa utilizada, incluindo indicação, tempo de uso, forma de utilização, obtenção e pagamento; gastos mensais com medicamentos e motivos referidos para a não utilização dos medicamentos prescritos.

- Seção F - Uso e acesso a serviços: serviços de saúde utilizados, públicos ou privados, nos últimos meses e ocorrência de hospitalização, atendimento ambulatorial, exames nos últimos quatro meses, 
bem como tempo de espera para atendimento, terapêutica prescrita e gastos relacionados.

○ Seção G - Rede de apoio familiar e social: número e características de pessoas que vivem com o idoso no mesmo domicílio (sexo, parentesco, estado marital, idade, escolaridade e condição de trabalho); assistência prestada ao idoso e fornecida por ele referente a cada membro citado; tempo gasto na ajuda ao idoso. As mesmas perguntas foram feitas em relação aos irmãos e filhos que não vivem no mesmo domicílio, bem como a outros familiares e que, de alguma forma, fornecem ou recebem ajuda do/ao idoso; assistência recebida ou fornecida nos últimos 12 meses de alguma instituição ou organização; participação do idoso em algum serviço voluntário ou organização comunitária.

- Seção H - História laboral e fontes de renda: trabalho atual (tipo, renda, razões para continuar trabalhando); caso não trabalhasse mais, por quê não o fazia, ocupação que teve durante o maior período de sua vida, horas trabalhadas, razões para mudar de atividade, aposentadoria, pensões, benefícios, outras fontes de renda, renda total pessoal e número de dependentes dessa renda; gastos pessoais (moradia, transporte, alimentação, vestimenta, saúde) e auto-avaliação de seu bem estar econômico.

- Seção J - Características da moradia: tipo e propriedade da moradia, condições de habitação (saneamento básico, luz, número de cômodos, bens presentes). 
- Seção K - Antropometria: altura do joelho, circunferência do braço, cintura, quadril, prega triciptal, peso, circunferência da panturrilha, largura do punho e força da mão.

- Seção L - Flexibilidade e Mobilidade: Provas de equilíbrio, mobilidade e flexibilidade.

As entrevistas foram realizadas em domicílio, sendo, em 2000, $88 \%$ respondidas diretamente pelo idoso. Em caso de dificuldade ou impossibilidade de o idoso responder aos questionamentos, por problemas físicos ou cognitivos, foi solicitado que uma pessoa próxima a ele o fizesse (NAZÁRIO, 2003).

A coleta de dados da Coorte A00 ocorreu entre janeiro de 2000 e março de 2001 em duas fases. Na primeira fase foram coletadas as informações das seções de $\mathrm{A}$ a $\mathrm{J}$, por uma equipe de 25 profissionais relacionados à área de saúde, que atuavam individualmente. Na segunda etapa as informações das sessões $L$ e $K$ foram coletadas por uma equipe de 12 estudantes de nutrição, que trabalhavam em dupla, devido às características dessas sessões, que incluíam mensurações antropométricas e testes de mobilidade e flexibilidade.

A descrição detalhada dos métodos empregados no estudo SABE pode ser encontrada no livro "O Projeto SABE no Município de São Paulo: uma abordagem inicial" (LEBRÃO e DUARTE, 2003) e os questionários empregados no estudo podem ser obtidos na íntegra em http://www.fsp.usp.br/sabe. 
Em 2006, a pesquisa teve continuidade apenas no município de São Paulo, transformando o Estudo SABE em um estudo longitudinal. Nesse momento, as 1.115 pessoas idosas entrevistadas em 2000 foram localizadas e reentrevistadas (Coorte $A_{06}$ ). A diferença foi composta por óbitos, mudanças para outros municípios, institucionalizações, não localizações e recusas.

A amostra utilizada nesse estudo foi composta por todos os idosos que não referiram comprometimento funcional em 2000 e que foram reentrevistados em 2006. Foram excluídos os idosos que relataram a ocorrência de doença cerebrovascular com sequelas no período para que o comprometimento funcional em decorrência dessa doença não fosse considerado.

Portanto, a amostra do presente estudo é composta por 336 idosos, que representam 162.913 idosos residentes na área urbana do município de São Paulo.

\subsection{Variáveis de Estudo}

3.2.1. Variável dependente 
O comprometimento funcional foi categorizado nesse estudo como:

(1) sem comprometimento;

(2) com dificuldade de mobilidade;

(3) com dificuldade em desempenhar as atividades de vida diária (AVDs).

Em caso de o idoso ter relado a dificuldade na mobilidade e nas atividades de vida diária, optou-se por incluí-lo na terceira categoria conforme o modelo de VERBRUGGE e JETTE (1994), que hipotetiza que a dificuldade na mobilidade precede as disfunções nas atividades de vida diária.

A dificuldade na mobilidade foi mensurada por meio de habilidades estudadas por ROSOW e BRESLAU (1966) e NAGI (1976), conforme proposto no Health and Retirement Study (HRS). Essas escalas incluem avaliação de mobilidade, força e capacidade motora fina, que exigem um amplo desempenho motor e força sendo mais complexos do que as habilidades necessárias para desenvolver as tarefas de autocuidado (atividades básicas de vida diária) e para manter uma vida comunitária independente (atividades instrumentais de vida diária) (FONDA e HERZOG, 2004).

Considerou-se como dificuldade de mobilidade a resposta "sim" ou "não pode" em pelo menos uma das seguintes habilidades:

(a) Tem alguma dificuldade para caminhar 1 rua (quadra)?

(b) Tem dificuldade em ficar sentado durante duas horas? 
(c) Tem dificuldade em se levantar da cadeira, depois de ficar sentado durante longo período?

(d) Encontra dificuldade em subir um andar pelas escadas sem descansar?

(e) Tem dificuldade em se curvar, se ajoelhar ou se agachar?

(f) Tem dificuldade para estender seus braços acima dos ombros?

(g) Encontra alguma dificuldade em levantar ou carregar pesos maiores que $5 \mathrm{~kg}$, como uma sacola de compras pesada?

(h) Tem dificuldade em levantar uma moeda da mesa?

Nesse estudo não se considerou a dificuldade em: (1) correr ou trotar cerca de $1 \mathrm{~km}$; caminhar diversões quarteirões e (2) subir vários lances de escada, por serem atividades relacionadas ao melhor desempenho aeróbico que exigem um grau elevado de força e mobilidade (FONDA e HERZOG, 2004)

Considerou-se como dificuldade nas atividades de vida diária a referência de pelo menos uma dificuldade no desempenho de alguma das seguintes atividades:

(1) caminhar a distancia de um cômodo,

(2) banhar-se,

(3) vestir-se,

(4) ir ao banheiro,

(5) transferir-se

(6) comer a partir de um prato colocado à sua frente

(7) administrar os próprios medicamentos, 
(8) utilizar o telefone,

(9) administrar as próprias finanças,

(10) fazer compras

(11) utilizar meios de transporte.

As atividades de 1 a 6 referem-se às atividades básicas de vida diária (ABVDs), sugeridas pelo índice de Independência de KATZ (KATZ et al., 1963), excluindo-se a avaliação de continência dos esfíncteres. As atividades de 7 a 11 correspondem às atividades instrumentais de vida diária, propostas por LAWTON (LAWTON e BRODY, 1969), excluindo-se as atividades com forte influência de gênero (preparar refeições quentes e atividades domésticas leve e pesadas), para evitar viés de resposta.

\subsubsection{Variáveis independentes}

3.2.2.1. Variável de interesse

A variável de interesse desse estudo foi doença articular referida, medida nos dois períodos do estudo por meio da seguinte pergunta: "Alguma vez o médico ou enfermeira Ihe disse que o(a) Sr(a) tem artrite, reumatismo, artrose?". As respostas possíveis foram sim, não, não sabe, não respondeu. De acordo com o relato da doença as respostas forma categorizadas em:

(1) não para a doença em 2000 e em 2006;

(2) não em 2000 e sim em 2006;

(3) sim em 2000 e 2006. 
Para facilitação da leitura deste estudo, denominaremos essas categorias como:

(1) sem doença articular;

(2) doença articular incidente e

(3) doença articular prevalente.

Considerando que o foco do estudo são as doenças articulares crônicas, os indivíduos que responderam "sim" em 2000 e "não" em 2006 não foram considerados na amostra selecionada.

\subsubsection{Covariáveis}

As covariáveis selecionadas conforme a resposta obtida no inquérito de 2000 foram: sexo, idade, escolaridade, percepção de suficiência de renda, arranjo domiciliar, posse de plano de saúde, sintomas depressivos (escala de Yesevage), declínio cognitivo (Folstein et al., 1975), obesidade ou sobrepeso (IMC $\geq 27$ ), doença crônica (hipertensão arterial, diabetes, câncer, osteoporose, doença pulmonar obstrutiva crônica, acidente vascular encefálico), ter sofrido internação nos últimos 4 meses anteriores à entrevista e ter sofrido queda nos últimos 12 meses anteriores à entrevista.

\subsection{Análise Estatística}

3.3.1. Modelo de regressão logística multinomial 
A análise dos dados foi feita por meio de estatística descritiva para cálculo das medidas de frequência seguida de análises bivariadas. A associação entre variáveis categóricas foi feita utilizando-se o teste de Rao Scott. Todas as variáveis que apresentaram $p<0,20$ na análise bivariada foram incluídas no modelo de Regressão Logística Multinomial utilizando-se o método de Stepwise Forward. Iniciou-se com a variável de interesse seguida das variáveis sociodemográficas e variáveis relacionadas às condições de saúde, de menor para maior p-valor. Foram mantidas no modelo as variáveis que apresentaram significância estatística ou que ajustaram o modelo. Considerou-se um nível de significância de $5 \%$ e foram estimados intervalos de confiança de $95 \%$. As análises foram feitas por meio do software SAS 9.2 considerando a análise de dados provenientes de amostras complexas. Após o modelo construído foi realizado o diagnóstico de fator de inflação de variância (FIV) para verificar a existência de multicolinearidade entre as variáveis que permaneceram. Considerou-se o teste positivo se a média do FIV > 0,10 (O’BRIEN, 2007).

\subsubsection{Risco atribuível}

Para estimar o efeito da doença articular no risco do comprometimento funcional foram calculados o risco atribuível, o risco atribuível proporcional e o risco atribuível populacional proporcional.

Considerou-se como desfecho o comprometimento funcional em

duas categorias: (1) sem comprometimento e (2) com algum 
comprometimento (dificuldade de mobilidade e/ou atividade de vida diária), para fins de cálculo dos riscos atribuíveis.

A exposição considerada para esse estudo foi a referência de doença articular em 2006. Optou-se por utilizar o relato desse inquérito para que fosse considerado também expostos os idosos que tiveram a doença diagnosticada entre os dois inquéritos.

O risco atribuível (RA) estima quantas das pessoas que ficaram limitadas foram em decorrência da doença articular. O seu cálculo é a diferença entre a incidência da limitação funcional nos expostos $\left(I_{e}\right)$ e a incidência da limitação funcional não expostos $\left(I_{n e}\right): R A=\left(I_{e}-I_{n e}\right) \cdot O$ risco atribuível, em porcentagem, significa a proporção da incidência do comprometimento funcional entre os idosos com doença articular deixaria de ocorrer se a doença articular fosse eliminada.

O risco atribuível proporcional expressa a proporção de pessoas com comprometimento funcional entre aqueles com a doença que podem ser atribuídos à doença. Sua fórmula de cálculo é: $\left(I_{e}-I_{n e}\right) / I_{e}$., ou seja, é a incidência do comprometimento funcional na população que poderia ser evitada se a doença articular fosse eliminada.

O risco atribuível proporcional populacional $\left(\mathrm{RAP}_{\mathrm{pop}}\right)$ estima esse risco na população, considerando a incidência da limitação na população $\left(I_{\text {pop }}\right)$ e entre os não expostos, considerando a seguinte fórmula: $R_{A} P_{p o p}=$ $\left(I_{\text {pop }}-I_{\text {ne }}\right) / I_{\text {pop }}$, sendo a incidência populacional $\left(I_{\text {pop }}\right)$ calculada:

$I_{\text {pop }}=\left(I_{e} \times P_{e}\right)+\left[I_{n e} \times\left(1-P_{e}\right)\right]$, onde:

$\mathrm{I}_{\mathrm{e}}$ : incidência da limitação funcional entre aqueles com doença articular $P_{\mathrm{e}}$ : prevalência da doença articular (relatada em 2006)

$I_{n e}$ : incidência da limitação funcional entre aqueles sem doença articular 
O RAP pop é a proporção da incidência do comprometimento funcional na população que poderia ser evitado se a doença articular fosse eliminada.

\subsection{Aspectos Éticos}

O Estudo SABE foi submetido e aprovado pelo Comitê de Ética da Faculdade de Saúde Pública da Universidade de São Paulo (COEP FSP/USP), conforme pareceres apresentados nos ofícios Of. COEP/67/99 de 24/05/1999 e Of. COEP/83/06 de 14/03/2006. Entrevistadores e participantes assinaram o termo de consentimento livre e esclarecido no momento da entrevista. 


\section{RESULTADOS}

\subsection{Perfil da Amostra}

Estima-se que a amostra de 336 idosos que não apresentaram comprometimento funcional em 2000 e reentrevistados em 2006 seja representativa de uma população de 162.913 idosos da população residente no município de São Paulo, no ano de 2000.

A amostra de idosos analisada nesse estudo em sua maioria é do sexo masculino (55,7\%), tem entre 60 e 69 anos $(74,1 \%)$, referem 4 anos ou mais de estudo ou mais $(67,4 \%)$ e moram acompanhados $(89,7 \%)$ (Tabela 1).

Em relação ao perfil de saúde no ano de 2000, observa-se a referência de sintomas depressivos em $9,5 \%$ dos idosos, $4,2 \%$ com declínio cognitivo, $29,1 \%$ foram classificados com sobrepeso ou obesidade e $51,5 \%$ relataram pelo menos uma doença crônica. Ainda, 17,3\% a ocorrência de queda no último ano antecedente à entrevista e 1,7\% referiram ter sido hospitalizados nos 4 meses anteriores à entrevista. Além disso, 66,9\% desses idosos consideram-se com um estado de saúde muito bom ou bom (Tabela 1).

Exceto possuir plano de saúde arranjo domiciliar, as demais variáveis apresentaram diferenças estatísticas em relação a amostra selecionada para o presente e a amostra original do estudo SABE, em 2000 (Tabela 1). 
Tabela 1: Distribuição (\%) dos idosos segundo participação na amostra selecionada para o estudo, segundo variáveis sociodemográficas e de saúde selecionadas. São Paulo, 2000-2006.

\begin{tabular}{|c|c|c|c|c|}
\hline \multirow[b]{2}{*}{ Variáveis (em 2000) } & \multirow{2}{*}{ Total } & \multicolumn{2}{|c|}{ Imostra selecionada } & \multirow[b]{2}{*}{ p-valor } \\
\hline & & Sim & Não & \\
\hline \multicolumn{5}{|l|}{ Doença articular } \\
\hline Não & 72,8 & 91,5 & 68,3 & \\
\hline Sim & 27,2 & 8,5 & 31,7 & $<0,001$ \\
\hline \multicolumn{5}{|l|}{ Sexo } \\
\hline Feminino & 58,6 & 44,3 & 62,1 & \\
\hline Masculino & 41,4 & 55,7 & 37,9 & $<0,001$ \\
\hline \multicolumn{5}{|l|}{ Idade } \\
\hline 60-69 anos & 59,1 & 74,1 & 55,4 & \\
\hline \multicolumn{4}{|l|}{ Escolaridade } & $<0,001$ \\
\hline Sem escolaridade & 19,7 & 9,8 & 22,1 & \\
\hline 1 a 3 anos & 25,5 & 22,8 & 26,1 & \\
\hline \multicolumn{5}{|c|}{ Percepção de Suficiência de renda } \\
\hline $\operatorname{Sim}$ & 31,4 & 38,3 & 29,7 & \\
\hline Não & 68,6 & 61,7 & 70,3 & 0,00 \\
\hline \multicolumn{5}{|l|}{ Arranjo Domiciliar } \\
\hline Mora sozinho & 13,2 & 10,3 & 14 & \\
\hline Mora acompanhado & 86,8 & 89,7 & 86 & 0,05 \\
\hline \multicolumn{5}{|l|}{ Plano de saúde } \\
\hline Não & 56,3 & 52,4 & 57,3 & \\
\hline Sim & 43,7 & 47,6 & 42,7 & 0,07 \\
\hline \multicolumn{5}{|l|}{ Sintomas } \\
\hline Não & 81 & 90,5 & 78,5 & \\
\hline Sim & 19 & 9,5 & 21,5 & $<0,001$ \\
\hline \multicolumn{5}{|l|}{ Declínio Cognitivo } \\
\hline Não & 86,8 & 95,8 & 84,7 & \\
\hline $\operatorname{Sim}$ & 13,2 & 4,2 & 15,3 & $<0,001$ \\
\hline \multicolumn{5}{|c|}{ Sobrepeso ou Obesidade } \\
\hline Não & 59,1 & 70,9 & 55,9 & \\
\hline Sim & 40,9 & 29,1 & 44,1 & 0,00 \\
\hline \multicolumn{5}{|l|}{ Estado de Saúde } \\
\hline Positiva & 47,9 & 66,9 & 42,7 & \\
\hline Negativa ou Neutra & 52,1 & 33,1 & 57,3 & $<0,001$ \\
\hline \multicolumn{5}{|l|}{ Doença Crônica } \\
\hline Nenhuma & 28,4 & 48,5 & 23,5 & \\
\hline Uma & 33,7 & 37,4 & 32,8 & \\
\hline Duas ou mais & 37,9 & 14,1 & 43,7 & $<0,001$ \\
\hline \multicolumn{5}{|c|}{ Queda nos últimos 12 meses anteriores à entrevista } \\
\hline Não & 71,4 & 82,7 & 68,7 & \\
\hline $\operatorname{Sim}$ & 28,6 & 17,3 & 31,3 & $<0,001$ \\
\hline \multicolumn{5}{|c|}{ Internação nos 4 meses anteriores à entrevista } \\
\hline Não & 95,2 & 98,3 & 94,4 & \\
\hline $\operatorname{Sim}$ & 4,8 & 1,7 & 5,6 & 0,01 \\
\hline Total & 100 & 19,5 & 80,5 & \\
\hline
\end{tabular}

Fonte: Estudo SABE, São Paulo, 2000 e 2006. 
4.2. Análise Descritiva da Incidência do Comprometimento Funcional

Entre os idosos da amostra desse estudo, 47,8\% relataram dificuldade de mobilidade e 7,3\% dificuldade nas AVDs, no período entre 2000 e 2006. No que tange à doença articular, entre o período acompanhado (2000-2006), 8,4\% relataram a doença em 2000 (doença articular prevalente) e 15,2\% passaram a relatá-la em 2006 (doença articular incidente). Observa-se que tanto entre os idosos com a doença articular incidente ou prevalente houve uma maior incidência da dificuldade na mobilidade $(70,7 \%$ e $51,5 \%)$, enquanto entre os idosos que não referiram doença articular em nenhum dos períodos $(49,9 \%)$ permaneceram sem comprometimento funcional (Tabela 2).

Enquanto a proporção da incidência de dificuldade na mobilidade é maior no grupo dos idosos com a doença articular incidente $(70,7 \%$ ante $51,6 \%)$, a proporção de incidência na dificuldade nas AVDs é maior entre os idosos com doença articular prevalente (13,2\% ante 4,7\%) (Tabela 2$)$.

Tabela 2: Distribuição (\%) da incidência do comprometimento funcional entre os idosos segundo o relato de doença articular entre 2000 e 2006. São Paulo, 2000 e 2006.

\begin{tabular}{lrrrrrr}
$\begin{array}{l}\text { Doença Articular } \\
\text { entre 2000 e 2006 }\end{array}$ & $\begin{array}{c}\text { Sem } \\
\text { comprometimento }\end{array}$ & $\begin{array}{c}\text { Dificuldade } \\
\text { de } \\
\text { mobilidade }\end{array}$ & $\begin{array}{c}\text { Dificuldade de } \\
\text { desempenhar } \\
\text { as AVDs }\end{array}$ & Total & p-valor \\
\hline Não & 49,9 & 42,9 & 7,2 & 76,4 & \\
Incidente & 24,6 & 70,7 & 4,7 & 15,2 & 0,0118 \\
Prevalente & 35,2 & 51,6 & 13,2 & 8,4 & \\
\hline Total & 44,8 & $\mathbf{4 7 , 8}$ & 7,3 & 100,0 & \\
\hline
\end{tabular}

Fonte: Estudo SABE, São Paulo, 2000 e 2006. 
As informações sociodemográficas e de saúde de incidência do comprometimento funcional, segundo a dificuldade de mobilidade e de desempenho das atividades de vida diária, estão descritas na Tabela 3.

A incidência da dificuldade de mobilidade foi estimada em $47,8 \%$, acometendo $60,4 \%$ das mulheres e $37,8 \%$ dos homens, $50,8 \%$ dos idosos com 70 anos ou mais, $51,2 \%$ com escolaridade entre 1 e 3 anos de estudo, $72,8 \%$ dos idosos que referiram sintomas depressivos, $48,8 \%$ entre aqueles que apresentaram declínio cognitivo e 57,3\% entre os idosos com auto percepção de saúde negativa ou neutra.

A incidência da dificuldade em desempenhar as AVDs sempre foram as menores observadas, independente das características de saúde ou sociodemográficas. A proporção dessa incidência foi maior entre os homens (8,5\% ante $6,0 \%$, entre as mulheres), entre os idosos com 70 anos ou mais $(13,2 \%)$ comparativamente àqueles com idade entre 60 e 69 anos (5,3\%) e de $23,8 \%$ entre os idosos sem escolaridade. A maior proporção de incidência da dificuldade nas AVDs foi observada entre aqueles que apresentaram declínio cognitivo (33,2\% ante 6,2\%). 
Tabela 3: Distribuição (\%) da incidência do comprometimento funcional entre os idosos segundo as variáveis sociodemográficas e de saúde em 2000. São Paulo, 2000 e 2006.

\begin{tabular}{|c|c|c|c|c|}
\hline & $\begin{array}{c}\text { Sem } \\
\text { comprometimento }\end{array}$ & $\begin{array}{c}\text { Dificuldade de } \\
\text { mobilidade }\end{array}$ & $\begin{array}{c}\text { Dificuldade de } \\
\text { desempenhar AVDs }\end{array}$ & $\begin{array}{c}\mathrm{p}- \\
\text { valor }\end{array}$ \\
\hline \multicolumn{5}{|l|}{ Sexo } \\
\hline Feminino & 33,7 & 60,4 & 6 & 0,002 \\
\hline Masculino & 53,7 & 37,8 & 8,5 & \\
\hline \multicolumn{5}{|l|}{ Idade } \\
\hline $60-69$ anos & 48,0 & 46,7 & 5,3 & \\
\hline$\geq 70$ anos & 36,0 & 50,8 & 13,2 & 0,011 \\
\hline \multicolumn{5}{|l|}{ Escolaridade } \\
\hline Sem escolaridade & 29,3 & 46,9 & 23,8 & \\
\hline 1 a 3 anos & 37,7 & 51,2 & 11,1 & $<0,00$ \\
\hline 4 anos ou mais & 49,5 & 46,8 & 3,7 & \\
\hline \multicolumn{5}{|c|}{ Percepção de Suficiência de renda } \\
\hline $\operatorname{Sim}$ & 43,8 & 50,6 & 5,6 & \\
\hline Não & 45,6 & 45,9 & 8,5 & 0,597 \\
\hline \multicolumn{5}{|l|}{ Arranjo Domiciliar } \\
\hline Mora sozinho & 38,6 & 53,3 & 8,1 & 0,729 \\
\hline Mora acompanhado & 45,6 & 47,2 & 7,3 & \\
\hline \multicolumn{5}{|l|}{ Plano de saúde } \\
\hline Não & 43,9 & 47 & 9,1 & \\
\hline Sim & 45,9 & 48,7 & 5,4 & 0,397 \\
\hline \multicolumn{5}{|c|}{ Sintomas depressivos } \\
\hline Não & 47,4 & 45,5 & 7,1 & \\
\hline Sim & 16,8 & 72,8 & 10,4 & 0,016 \\
\hline \multicolumn{5}{|l|}{ Declínio Cognitivo } \\
\hline Não & 45 & 48,8 & 6,2 & \\
\hline $\begin{array}{l}\text { Sim } \\
\text { Sobrepeso ou }\end{array}$ & 41,7 & 24,8 & 33,5 & 0,002 \\
\hline Não & 46,6 & 43,8 & 9,6 & \\
\hline Sim & 43,4 & 52,7 & 3,9 & 0,120 \\
\hline \multicolumn{5}{|l|}{ Estado de Saúde } \\
\hline Positiva & 50,9 & 44,3 & 4,9 & 0,01 \\
\hline Negativa ou Neutra & 33,7 & 57,3 & 9,0 & \\
\hline \multicolumn{5}{|l|}{ Doença Crônica } \\
\hline Nenhuma & 48,9 & 42,4 & 8,6 & \\
\hline Uma & 43,9 & 47,8 & 8,3 & 0,133 \\
\hline Duas ou mais & 36,1 & 62,3 & 1,6 & \\
\hline \multicolumn{5}{|c|}{ Queda nos últimos 12 meses anteriores à entrevista } \\
\hline Não & 46 & 47,1 & 6,9 & 0,619 \\
\hline $\begin{array}{l}\text { Sim } \\
\text { Internação nos } 4 \mathrm{me}\end{array}$ & anteriores à & 51,2 & 9,6 & \\
\hline Não & 44,3 & 48,3 & 7,3 & 0,174 \\
\hline Sim & 75 & 17,3 & 7,8 & \\
\hline Total & 44,8 & 47,8 & 7,3 & \\
\hline
\end{tabular}

Fonte: Estudo SABE, São Paulo, 2000 e 2006. 
4.3. Análise Descritiva e Analítica da Incidência do Comprometimento de Mobilidade em Relação à Doença Articular

Os idosos que não apresentaram nenhuma dificuldade na mobilidade em 2000 e foram acompanhados em 2006 apresentaram em ordem decrescente as seguintes incidências das dificuldades para: ajoelhar ou agachar $(28,3 \%)$, carregar aproximadamente $5 \mathrm{~kg}$ de peso $(20,5 \%)$, levantar de uma cadeira $(17,7 \%)$, subir um lance de escada $(15,2 \%)$, puxar ou empurrar grandes objetos (13,9\%), ficar sentados por mais de duas horas $(9,7 \%)$, caminhar uma quadra $(5,2 \%)$, estender os braços acima dos ombros $(4,1 \%)$ e pegar uma moeda de uma mesa $(0,8 \%)$ (Tabela 4$)$.

Além disso, observou-se que as atividades de carregar uma sacola de $5 \mathrm{~kg}$, ajoelhar ou agachar, estender os braços acima dos ombros e puxar ou empurrar grandes objetos apresentam uma associação estatisticamente significativa com a doença articular.

Nos idosos que relataram a doença articular em 2006, a chance de apresentar dificuldade em carregar peso foi 2,3 vezes maior em relação aos que não referiram a doença e para a dificuldade em ajoelhar ou agachar esse risco foi 2,6 vezes maior.

Por outro lado, para os idosos que referiram a presença da doença em 2000, os riscos em apresentar dificuldades em estender os braços acima dos ombros e para puxar ou empurrar grandes objetos foram 7,7 e 2,7 (respectivamente) maiores em relação aos que não referiram a doença. 
Tabela 4: Distribuição (\%) e odds ratio da doença articular referida entre 2000 e 2006 segundo a incidência de dificuldade em ações de mobilidade selecionadas. São Paulo, 2000 e 2006.

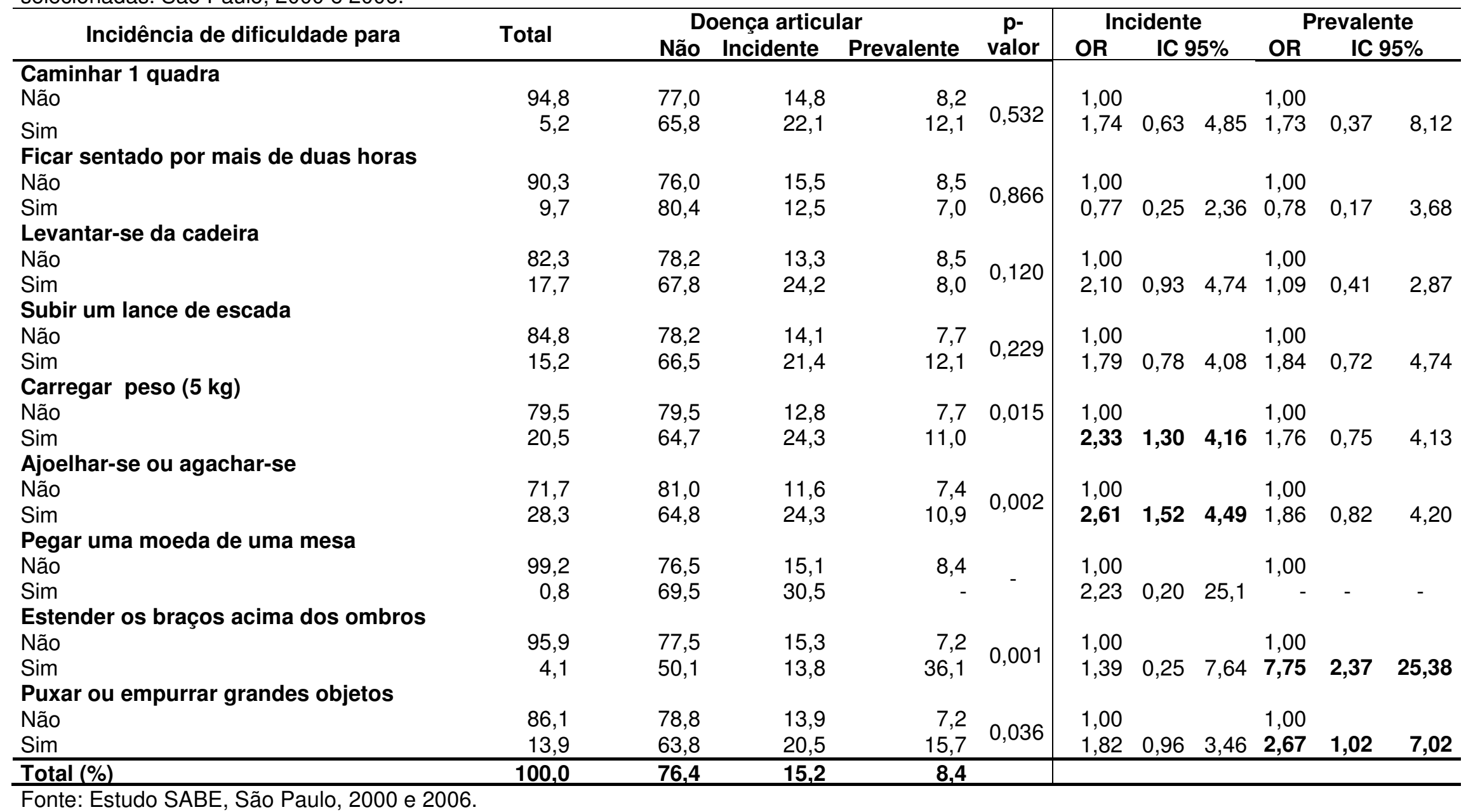


4.3.1. Análise descritiva e analítica da incidência do comprometimento das ações de mobilidade em relação à doença articular entre os homens

No sexo masculino, as maiores incidências das dificuldades foram nas ações de ajoelhar ou agachar (23,2\%), levantar de uma cadeira $(15,2 \%)$, carregar peso $(11,8 \%)$ e subir um lance de escada $(10,4 \%)$. As demais ações, como puxar ou empurrar grandes objetos, ficar sentado por mais de duas horas, caminhar uma quadra e pegar uma moeda apresentaram incidências entre $9,5 \%$ e 0,5\%. Entretanto, apenas as atividades de ajoelhar ou agachar apresentou diferença significativa em relação à doença articular (Tabela 5).

Entre os idosos que passaram a relatar a doença articular em 2006, o risco em apresentar dificuldade para ajoelhar-se ou agachar-se foi 2,5 vezes maior em relação àqueles que não apresentaram a doença, sem apresentar diferença estatística significativa para aqueles que relataram a doença desde 2000. 
Tabela 5: Distribuição (\%) e odds ratio da doença articular referida entre 2000 e 2006 segundo a incidência de dificuldade em ações de mobilidade selecionadas entre os homens. São Paulo, 2000 e 2006.

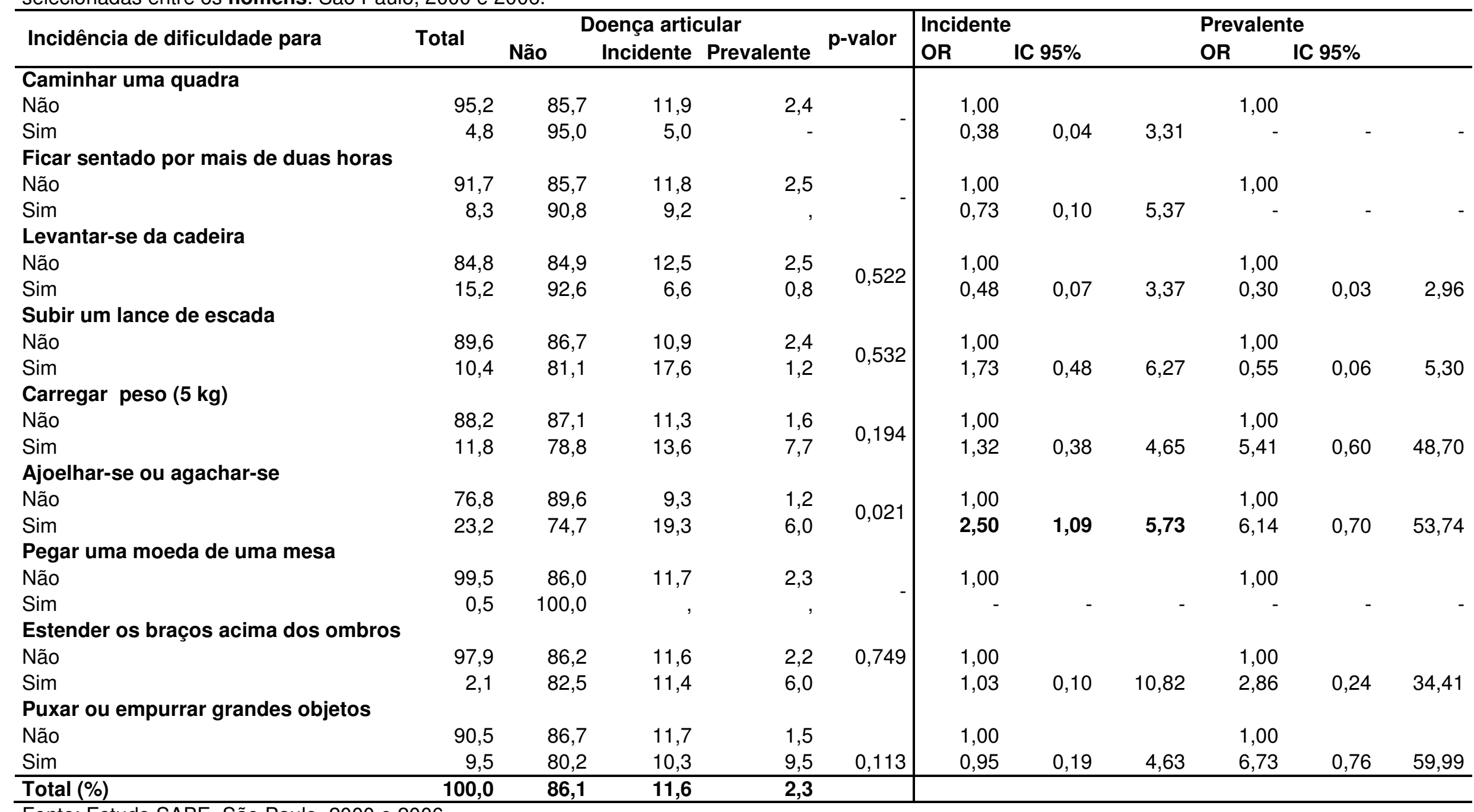

Fonte: Estudo SABE, São Paulo, 2000 e 2006. 
4.3.2. Análise descritiva e analítica da incidência do comprometimento das ações de mobilidade em relação à doença articular entre as mulheres

As incidências das dificuldades nas ações de mobilidade foram maiores entre as mulheres do que nos homens. Entretanto, diferente dos homens, observou-se uma associação estatisticamente significante entre a doença articular e as ações de levantar da cadeira e estender os braços acima dos ombros.

O risco em apresentar dificuldade para se levantar da cadeira foi 4,4 vezes maior entre aquelas que relataram a doença em 2006 em comparação àquelas que não relataram a doença. Ainda, o risco para estender os braços acima dos ombros foi de 6,3 vezes maior entre as idosas que relatavam a doença desde 2000.

As incidências das dificuldade nas ações de mobilidade e suas associações com a doença articular estão descritas na Tabela 6. 
Tabela 6: Distribuição (\%) e odds ratio da doença articular referida entre 2000 e 2006 segundo a incidência de dificuldade em ações de mobilidade selecionadas entre as mulheres. São Paulo, 2000 e 2006.

\begin{tabular}{|c|c|c|c|c|c|c|c|c|c|c|c|}
\hline \multirow{2}{*}{$\begin{array}{l}\text { Incidência de dificuldade para } \\
\text { Caminhar uma quadra }\end{array}$} & \multirow{2}{*}{ Total } & \multicolumn{3}{|c|}{ Doença articular } & \multirow{2}{*}{ p-valor } & \multirow{2}{*}{\multicolumn{3}{|c|}{ Incidente }} & \multicolumn{3}{|c|}{ Prevalente } \\
\hline & & Não & Incidente & Prevalente & & \multicolumn{2}{|c|}{ OR IC $95 \%$} & & OR & \multicolumn{2}{|c|}{ IC $95 \%$} \\
\hline Não & 94,3 & 66,0 & 18.5 & 155 & \multirow{3}{*}{0,156} & 100 & & & 100 & & \\
\hline Sim & 57 & 347 & 403 & 050 & & 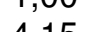 & & & 1,0 & & \\
\hline Ficar sentado por mais de duas horas & & 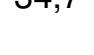 & $40, v$ & $2 v, v$ & & 4,10 & 0,89 & 19,35 & $0,0 T$ & 0,54 & 17,50 \\
\hline Não & 88,6 & 63,4 & 20,2 & 16,4 & & 1,00 & & & 1,00 & & \\
\hline Sim & 11,4 & 70,9 & 15,6 & 13,5 & 0,846 & 0,69 & 0,17 & 2,88 & 0,74 & 0,14 & 3,97 \\
\hline Levantar-se da cadeira & & & & & & & & & & & \\
\hline Não & 79,3 & 69,3 & 14,3 & 16,4 & & 1,00 & & & 1,00 & & \\
\hline Sim & 20,7 & 45,0 & 40,5 & 14,6 & 0,013 & 4,36 & 1,36 & 13,97 & 1,37 & 0,41 & 4,54 \\
\hline Subir um lance de escada & & & & & & & & & & & \\
\hline Não & 78,7 & 66,0 & 18,6 & 15,3 & 0723 & 1,00 & & & 1,00 & & \\
\hline $\begin{array}{l}\text { Sim } \\
\text { Carregar peso }(5 \mathrm{~kg})\end{array}$ & 21,3 & 57,6 & 23,7 & 18,7 & 0,123 & 1,46 & 0,45 & 4,71 & 1,40 & 0,52 & 3,78 \\
\hline Não & 80,6 & 67,5 & 17,1 & 15,4 & & 1,00 & & & 1,00 & & \\
\hline $\begin{array}{l}\text { Sim } \\
\text { Ajoelhar-se ou agachar-se }\end{array}$ & 19,4 & 53,7 & 26,9 & 19,5 & 0,140 & 2,22 & 0,81 & 6,11 & 0,82 & 0,35 & 1,96 \\
\hline Não & 65,1 & 68,3 & 15,1 & 16,6 & 0,144 & 1,00 & & & 1,00 & & \\
\hline $\begin{array}{l}\text { Sim } \\
\text { Pegar uma moeda de uma mesa }\end{array}$ & 34,9 & 56,6 & 28,4 & 15,1 & & 2,27 & 0,93 & 5,54 & 1,10 & 0,44 & 2,77 \\
\hline Não & 98,9 & 64,4 & 19,4 & 16,2 & & 1,00 & & & 1,00 & & \\
\hline $\begin{array}{l}\text { Sim } \\
\text { Estender os braços acima dos ombros }\end{array}$ & 1,1 & 52,6 & 47,4 & , & - & 2,99 & 0,23 & 39,20 & - & - & - \\
\hline Não & 93,5 & 66,1 & 20,1 & 13,8 & 0,0339 & 1,00 & & & 1,00 & & \\
\hline Sim & 6,5 & 36,8 & 14,7 & 48,5 & & 1,32 & 0,14 & 12,43 & 6,31 & 1,40 & 28,49 \\
\hline Puxar ou empurrar grandes objetos & & & & & & & & & & & \\
\hline Não & 80,6 & 67,5 & 17,1 & 15,4 & & 1,00 & & & 1,00 & & \\
\hline Sim & 19,4 & 53,7 & 26,9 & 19,5 & 0,1402 & 1,44 & 0,34 & 6,15 & 0,73 & 0,14 & 3,97 \\
\hline Total & 100,0 & 81,8 & 12,8 & 5,4 & & & & & & & \\
\hline
\end{tabular}

Fonte: Estudo SABE, São Paulo, 2000 e 2006. 
4.3.3. Análise descritiva e analítica da incidência do comprometimento das ações de mobilidade em relação à doença articular entre idosos com idade entre 60 e 69 anos

Conforme se observa na Tabela 6, os idosos mais jovens que não apresentaram nenhuma dificuldade na mobilidade em 2000 e foram acompanhados em 2006 apresentaram em ordem decrescente as seguintes incidências da dificuldade para: ajoelhar ou agachar (25,8\%), carregar peso $(16,7 \%)$, levantar de uma cadeira $(16,0 \%)$, puxar ou empurrar grandes objetos $(13,8 \%)$ subir um lance de escada $(10,8 \%)$, ficar sentado por mais de duas horas $(10,2 \%)$, estender os braços acima dos ombros $(4,8 \%)$, caminharem 1 quadra $(2,8 \%)$ e pegar uma moeda de uma mesa $(0,6 \%)$.

Entretanto, constatou-se uma associação estatisticamente significante entre a doença articular e as ações de ajoelhar ou agachar e estender os braços acima dos ombros. Enquanto o risco em apresentar dificuldade para ajoelhar ou agachar foi 3,23 vezes maior entre aqueles que relataram a doença em 2006 em comparação aqueles que não relataram a doença, o risco para estender os braços acima dos ombros foi de 6,73 vezes maior entre aqueles que referiram a doença em 2000. 
Tabela 7: Distribuição (\%) e odds ratio da doença articular referida entre 2000 e 2006 segundo a incidência de dificuldade em ações de mobilidade selecionadas na faixa etária entre 60 e 69 anos. São Paulo, 2000 e 2006.

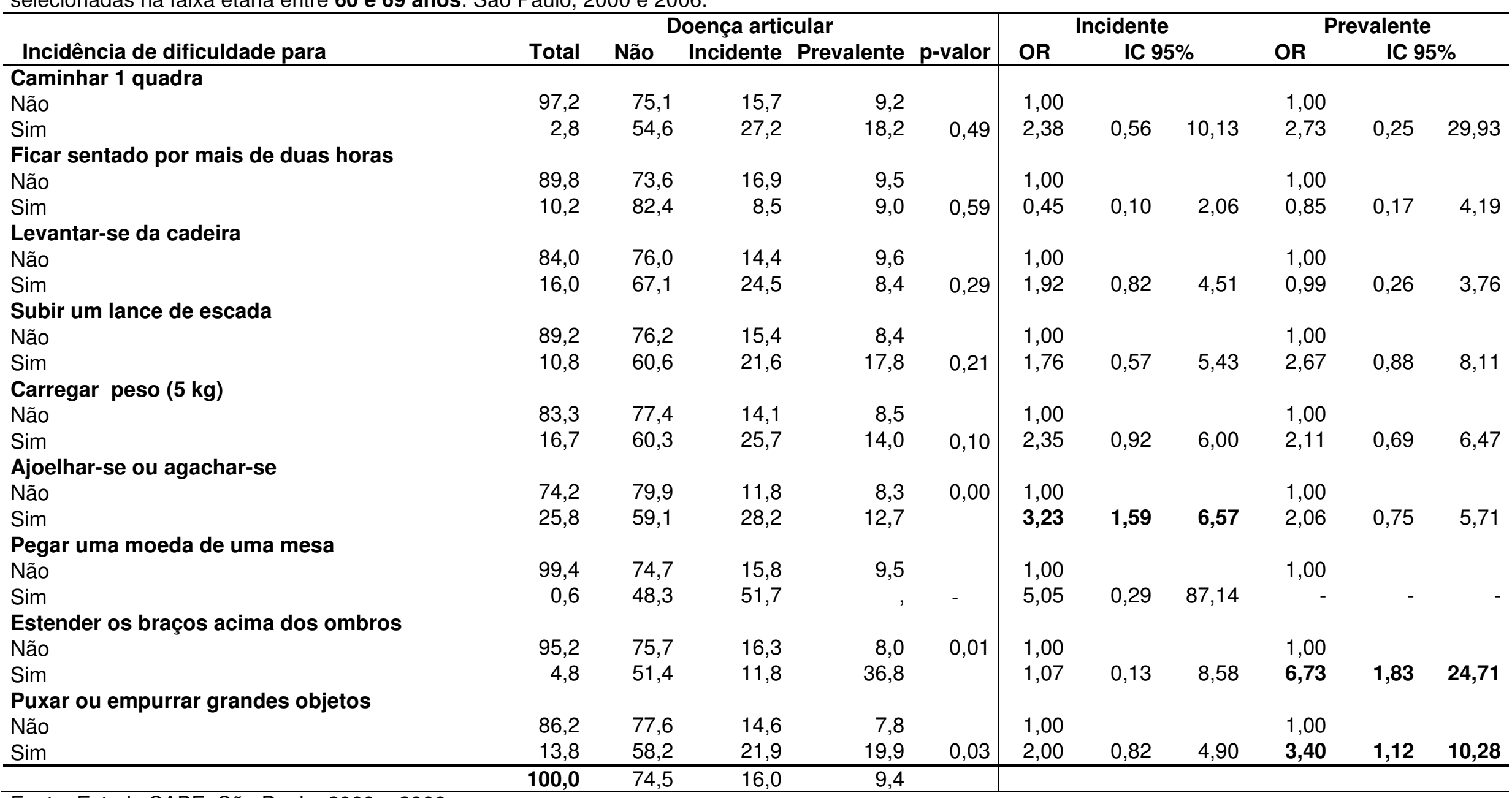

Fonte: Estudo SABE, São Paulo, 2000 e 2006. 
4.3.4. Análise descritiva e analítica da incidência do comprometimento das ações de mobilidade em relação à doença articular entre idosos com idade a partir de 70 anos

Entre os idosos com idade mais avançada, houve uma maior incidência de dificuldade nas ações de mobilidade na maioria das ações em comparação aos mais jovens (Tabela 8), exceto nas ações de ficar sentado por mais de duas horas e estender os braços acima dos ombros. Entretanto, apenas esta última apresentou diferença significativa em relação à doença articular entre esses idosos mais velhos, sendo 13 vezes maior entre aqueles que relatavam a doença desde 2000.

As incidências das dificuldades nas ações de mobilidade e suas associações com a doença articular estão detalhadas na Tabela 8. 
Tabela 8: Distribuição (\%) e odds ratio da doença articular referida entre 2000 e 2006 segundo a incidência de dificuldade em ações de mobilidade selecionadas na faixa etária a partir de 70 anos. São Paulo, 2000 e 2006

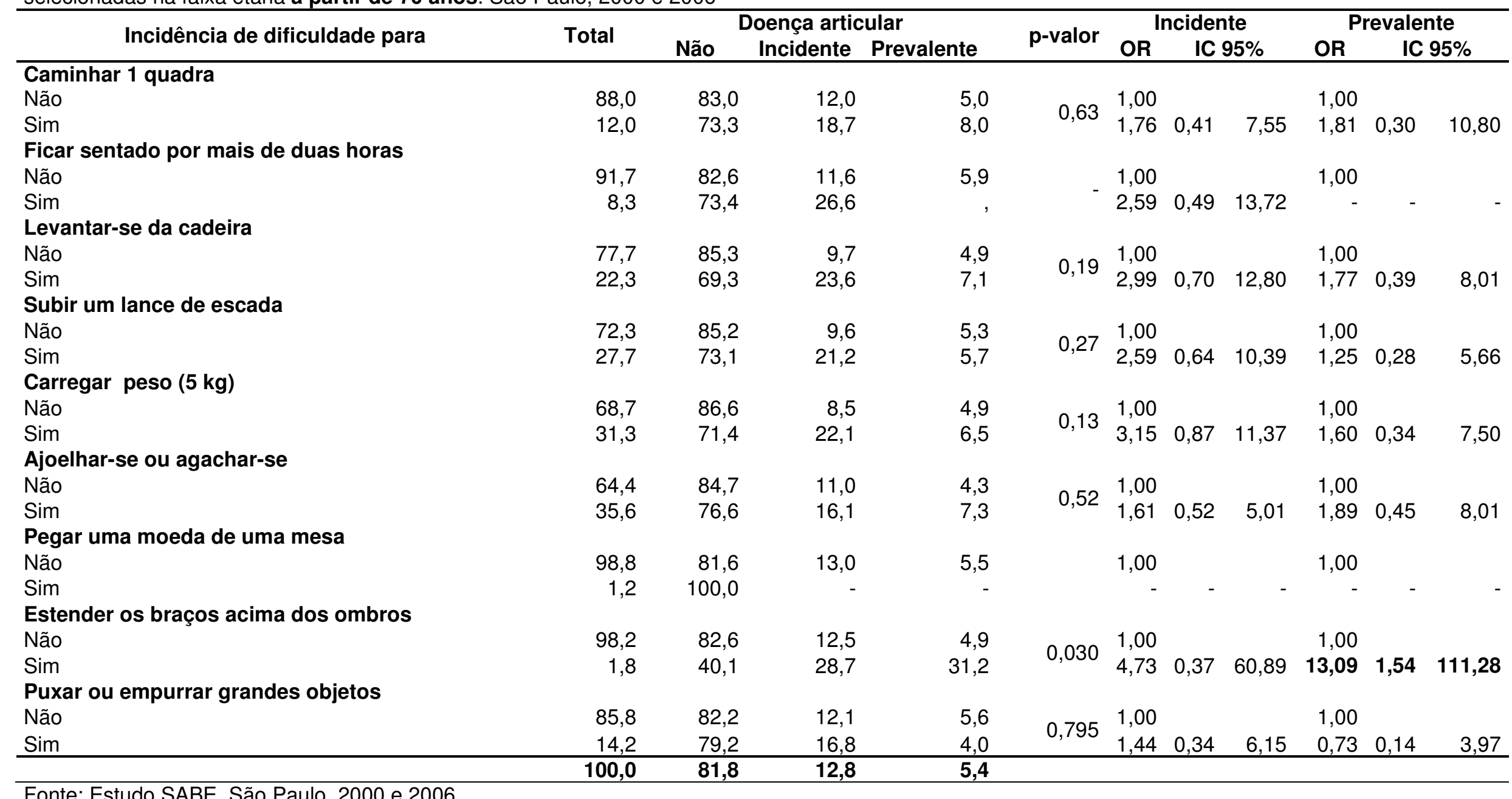

Fonte: Estudo SABE, São Paulo, 2000 e 2006. 


\subsection{Fatores Associados aos Níveis de Comprometimento Funcional}

A incidência da dificuldade de mobilidade foi associada à doença articular incidente, entretanto, após os ajustes pelos fatores de saúde essa associação perdeu significância. Entre as variáveis estudadas, o sexo feminino associado à dificuldade na mobilidade, independentemente. Os valores do odds ratio dessas e das demais variáveis estão descritos na Tabela 9.

Tabela 9: Modelo de regressão logística multinomial para incidência de dificuldade na mobilidade segundo a doença articular referida em 2000 e em 2006. São Paulo, 2000 e 2006.

\begin{tabular}{|c|c|c|c|c|c|c|c|c|c|c|c|c|}
\hline \multirow{2}{*}{ Variáveis } & \multicolumn{4}{|c|}{ Não ajustado } & \multicolumn{4}{|c|}{$\begin{array}{c}\text { (+) variáveis } \\
\text { sociodemográficas }\end{array}$} & \multicolumn{4}{|c|}{ (+) variáveis de saúde } \\
\hline & OR & $\mathrm{ICI}$ & ICS & $\begin{array}{c}\text { p- } \\
\text { valor }\end{array}$ & OR & $\mathrm{ICI}$ & ICS & $\begin{array}{c}\mathrm{p}- \\
\text { valor }\end{array}$ & OR & $\mathrm{ICI}$ & ICS & $\begin{array}{c}p- \\
\text { valor }\end{array}$ \\
\hline \multicolumn{13}{|c|}{ Doença Articular } \\
\hline Sem doença & 1,00 & & & & 1,00 & & & & 1,00 & & & \\
\hline Incidente & 3,35 & 1,32 & 8,51 & 0,01 & 3,02 & 1,14 & 7,96 & 0,03 & 2,88 & 0,95 & 8,67 & 0,06 \\
\hline Prevalente & 1,32 & 0,29 & 5,97 & 0,72 & 1,18 & 0,42 & 3,33 & 0,76 & 1,28 & 0,43 & 3,78 & 0,66 \\
\hline \multicolumn{13}{|l|}{ Idade } \\
\hline $60-69$ & & & & & 1,00 & & & & 1,00 & & & \\
\hline 70 ou mais & & & & & 1,50 & 0,91 & 2,46 & 0,11 & 1,63 & 0,96 & 2,77 & 0,07 \\
\hline \multicolumn{13}{|l|}{ Sexo } \\
\hline Feminino & & & & & 2,35 & 1,29 & 4,27 & 0,01 & 2,27 & 1,17 & 4,40 & 0,02 \\
\hline Masculino & & & & & 1,00 & & & & 1,00 & & & \\
\hline \multicolumn{13}{|l|}{ Escolaridade } \\
\hline Sem escolarida & & & & & 1,59 & 0,58 & 4,36 & 0,36 & 1,16 & 0,39 & 3,40 & 0,79 \\
\hline 1 a 3 anos de $\epsilon$ & tudo & & & & 1,37 & 0,81 & 2,32 & 0,24 & 1,46 & 0,78 & 2,76 & 0,24 \\
\hline 4 anos ou mais & & & & & 1,00 & & & 1,00 & 1,00 & & & \\
\hline \multicolumn{13}{|c|}{ Declínio Cognitivo } \\
\hline Não & & & & & & & & & 1,00 & & & \\
\hline Sim & & & & & & & & & 0,19 & 0,02 & 2,21 & 0,19 \\
\hline \multicolumn{13}{|c|}{ Sobrepeso ou Obesidade } \\
\hline Não & & & & & & & & & 1,00 & & & \\
\hline Sim & & & & & & & & & 1,04 & 0,60 & 1,78 & 0,90 \\
\hline \multicolumn{13}{|c|}{ Doença Crônica } \\
\hline Nenhuma & & & & & & & & & 1,00 & & & \\
\hline Uma & & & & & & & & & 1,22 & 0,68 & 2,20 & 0,51 \\
\hline Duas ou mais & & & & & & & & & 1,91 & 0,93 & 3,89 & 0,08 \\
\hline
\end{tabular}

Fonte: Estudo SABE, São Paulo, 2000 e 2006. 
Em contrapartida, a incidência da dificuldade em realizar as atividades de vida diária não foi associada à doença articular, independente dos ajustes. Observou-se no modelo final (Tabela 10) que o baixo nível de escolaridade (tanto de 1 a 3 anos de estudo quanto sem escolaridade) e a idade mais avançada (a partir de 70 anos) foram associados à incidência da dificuldade nas atividades de vida diária.

Tabela 10: Modelo de regressão logística multinomial para incidência de dificuldade nas atividades de vida diária segundo a doença articular referida em 2000 e em 2006. São Paulo, 2000 e 2006.

\begin{tabular}{|c|c|c|c|c|c|c|c|c|c|c|c|c|}
\hline \multirow{2}{*}{ Variáveis } & \multicolumn{3}{|c|}{ Não ajustado } & \multirow[b]{2}{*}{$\begin{array}{c}\text { p- } \\
\text { valor }\end{array}$} & \multicolumn{4}{|c|}{$\begin{array}{c}\text { (+) variáveis } \\
\text { sociodemográficas }\end{array}$} & \multicolumn{4}{|c|}{ (+) variáveis de saúde } \\
\hline & OR & ICI & ICS & & OR & $\mathrm{ICI}$ & ICS & $\begin{array}{c}\text { p- } \\
\text { valor }\end{array}$ & OR & $\mathrm{ICI}$ & ICS & $\begin{array}{c}\text { p- } \\
\text { valor }\end{array}$ \\
\hline \multicolumn{13}{|c|}{ Doença Articular } \\
\hline Sem doença & 1,00 & & & & 1,00 & & & & 1,00 & & & \\
\hline Incidente & 1,70 & 0,69 & 4,24 & 0,25 & 1,45 & 0,31 & 6,81 & 0,64 & 1,60 & 0,32 & 8,08 & 0,57 \\
\hline \multicolumn{13}{|l|}{ Idade } \\
\hline $60-69$ & & & & & 1,00 & & & & 1,00 & & & \\
\hline 70 ou mais & & & & & 3,01 & 1,34 & 6,76 & 0,01 & 3,27 & 1,39 & 7,74 & 0,01 \\
\hline \multicolumn{13}{|l|}{ Sexo } \\
\hline Feminino & & & & & 0,90 & 0,29 & 2,80 & 0,85 & 1,00 & 0,30 & 3,37 & 1,00 \\
\hline Masculino & & & & & 1,00 & & & & 1,00 & & & \\
\hline \multicolumn{13}{|l|}{ Escolaridade } \\
\hline Sem escolarid & & & & & 8,99 & 3,79 & 21,35 & $<0,01$ & 5,94 & 1,81 & 19,51 & 0,00 \\
\hline 1 a 3 anos de & udo & & & & 3,80 & 1,32 & 10,88 & 0,01 & 3,85 & 1,16 & 12,82 & 0,03 \\
\hline 4 anos ou mais & & & & & & & & & 1,00 & & & \\
\hline \multicolumn{13}{|c|}{ Declínio Cognitivo } \\
\hline Não & & & & & & & & & 1,00 & & & \\
\hline Sim & & & & & & & & & 3,01 & 0,34 & 26,64 & 0,32 \\
\hline \multicolumn{13}{|c|}{ Sobrepeso ou Obesidade } \\
\hline Não & & & & & & & & & 1,00 & & & \\
\hline Sim & & & & & & & & & 0,44 & 0,11 & 1,84 & 0,26 \\
\hline \multicolumn{13}{|c|}{ Doença Crônica } \\
\hline Nenhuma & & & & & & & & & 1,00 & & & \\
\hline Uma & & & & & & & & & 1,17 & 0,35 & 3,93 & 0,80 \\
\hline Duas ou mais & & & & & & & & & 0,31 & 0,06 & 1,54 & 0,15 \\
\hline
\end{tabular}

Fonte: Estudo SABE, São Paulo, 2000 e 2006. 
Ainda, em relação ao modelo final, a idade $(p=<0,001)$, o sexo ( $p$-valor $=0,02)$, escolaridade $(p$-valor $=0,02)$ e declínio cognifivo $(p$-valor=0,01) foram variáveis que foram significativas no modelo da incidência de níveis de comprometimento funcional.

\subsection{Risco de Comprometimento Funcional Atribuível à Doença Articular}

A incidência do comprometimento funcional, independente do seu grau foi de $55,2 \%$ entre 2000 e 2006 . A incidência do comprometimento funcional foi de $71,6 \%$ entre os idosos com a doença articular referida em 2006, enquanto entre aquele que não relataram essa doença a incidência foi de $50,1 \%$, sendo essa diferença estatisticamente significante $(p$-valor $=0,01)$, conforme descrito na Tabela 11. Observou-se que a proporção de idosos que referiram a doença articular em 2006 foi de 23,6\% (dados não mostrados).

Tabela 11: Incidência da comprometimento funcional e doença articular, segundo ao ano de relato da doença articular.

\begin{tabular}{ccccc}
\hline \multirow{2}{*}{$\begin{array}{c}\text { Doença Articular } \\
(\mathbf{2 0 0 6})\end{array}$} & \multicolumn{2}{c}{ Comprometimento funcional } & \multirow{2}{*}{ Total } & p-valor \\
\cline { 2 - 3 } & $\mathbf{S i m}$ & $\mathbf{N a ̃ o}$ & & \\
\hline Sim & 71,6 & 28,4 & 100,0 & \multirow{2}{*}{0,01} \\
Não & 50,1 & 49,9 & 100,0 & \\
\hline Total & $\mathbf{5 5 , 2}$ & $\mathbf{4 4 , 8}$ & $\mathbf{1 0 0 , 0}$ & \\
\hline
\end{tabular}

Fonte: Estudo SABE, São Paulo, 2000 e 2006.

Dessa forma, considera-se que se fosse possível evitar a doença articular, estima-se que a probabilidade do comprometimento funcional das pessoas idosas cairia para $21,5 \%$. Ainda, entre os idosos que relataram a 
doença articular, $30,1 \%$ da incidência do comprometimento funcional pode ser atribuído à doença articular.

Portanto, considerando as condições de saúde da população em 2000, de cada 100 idosos, estima-se que 9,2\% da incidência do comprometimento funcional na população idosa de São Paulo poderia ser evitada se a doença articular fosse eliminada (Quadro 1).

Quadro 1: Riscos atribuíveis à doença articular no comprometimento funcional, segundo a doença articular referida em 2006.

\begin{tabular}{|lc|}
\hline \multicolumn{2}{|c|}{ Risco atribuível à doença articular } \\
\hline Risco atribuível & $21,5 \%$ \\
Risco atribuível proporcional & $30,1 \%$ \\
Risco atribuível proporcional populacional & $9,2 \%$ \\
\hline
\end{tabular}

Fonte: Estudo SABE, São Paulo, 2000 e 2006. 


\section{DISCUSSÃO}

No presente estudo, a incidência do comprometimento funcional foi de $52,2 \%$, sendo $47,8 \%$ para a dificuldade de mobilidade e $7,3 \%$ para a dificuldade em desempenhar as AVDs.

Em relação à dificuldade na mobilidade, a incidência observada foi maior do que a encontrada por CHAUDHRY et al. (2010) (30,0\%). Apesar do tempo de seguimento ter sido semelhante entre os estudos (5 e 6 anos), os critérios adotados para a definição de comprometimento nesse estudo foi menos abrangente no estudo de CHAUDHRY et al. (2004), considerando apenas a dificuldade em subir um lance de escada ou andar 1 quadra.

Se considerarmos um comprometimento funcional progressivo, esses resultados sugerem que existe uma grande probabilidade de os idosos virem a desenvolver a dificuldade nas AVDs ao passar dos anos, pois no período acompanhado, quase a metade dos idosos sem comprometimento passaram a apresentar dificuldade de mobilidade.

Quanto à incidência da dificuldade nas AVDs, esta foi menor $(7,3 \%)$ em relação a alguns estudos longitudinais, que observaram incidência de 15,0\% (CHAUDHRY et al., 2010), 26,7\% (TAS el al., 2007) e 28,9\% (REYNOLDS e SILVERSTEIN, 2003).

REYNOLDS e SILVERSTEIN (2003), que também observaram a incidência de dificuldade da mobilidade nesse estudo, relataram uma incidência de $28,9 \%$ em pelo menos alguma atividade instrumental de vida diária. A incidência das atividades básicas de vida diária variou entre 7,3\% (comer) e 
14,8\% (banhar-se). Apesar de estudarem a mobilidade e as AVDs em um mesmo estudo, a amostra para cada tipo de comprometimento foi diferenciada, dessa forma, os idosos que não tinham limitação nas AVDs no início do seguimento poderiam ter comprometimento da mobilidade, o que não ocorreu em nosso estudo.

TAS et al. (2007) observaram uma incidência maior $(26,7 \%)$ em relação ao presente estudo, entretanto, semelhante ao estudo de REYNOLDS e SILVERSTEIN (2003). Ambos os estudos partem de uma amostra de idosos a partir de 55 anos de idade e livre de dificuldade somente para o desempenho de funções das atividades de vida diária (instrumentais ou básicas).

Em contrapartida, com uma população mais envelhecida (a partir de 65 anos), CHAUDHRY et al. (2010) observaram uma incidência relativamente menor (15,0\%), apesar do critério de seleção da amostra ter sido semelhante ao de TAS et al. (2007) e REYNOLDS e SILVERSTEIN (2003) e o tempo de seguimento semelhantes (5 e 6 anos).

A estimativa da incidência comprometimento funcional pode variar em função do critério usado na sua definição e no tempo de seguimento da coorte. Observa-se que as incidências são maiores quando não se excluem da amostra os idosos com dificuldade de mobilidade no início do seguimento. Além disso, quando o tempo de seguimento é semelhante, as incidências tendem a ser próximas, em diferentes estudos. Para o seguimento de 6 anos, LIN et al. (2010) observaram uma incidência superior aos demais estudos $(22,0 \%)$ por observar apenas idosas, já SONG et al. (2006) estimaram incidência de $17,7 \%$ para uma coorte de ambos os sexos. Entanto, quando 
tempo de observação é menor, a incidência da dificuldade em desempenhar as atividades de vida diária foi estimada em 7,4\% para o período de 2 anos.

Quando esses resultados são analisados em relação à referência da doença articular em 2000 e 2006, a incidência de dificuldade na mobilidade foi elevada tanto para aqueles com a doença articular incidente $(70,7 \%)$ quanto para aqueles com a doença articular prevalente $(51,6 \%)$, enquanto a incidência da dificuldade para as AVDs foi de $4,7 \%$ e $13,2 \%$ para a doença articular incidente e prevalente, respectivamente. Quanto à dificuldade de mobilidade, LING et al. (2006) observou uma incidência de 22,0\%. A incidência de dificuldade em desempenhar as AVDs do presente estudo também foi menor do que as encontradas no estudo de LING et al. (2006), de 22,0\%, entretanto, maior do que a observada no estudo de SONG et al. (2006), de 9,3\%. Nota-se no estudo de LING et al. (2006) que a amostra estuda foi somente de mulheres entre 70 e 79 anos, apesar do tempo de seguimento ter sido de 6 anos.

Contudo, quando se verificou no presente estudo a associação entre o comprometimento funcional e a doença articular não foi encontrada associação significativa, independente do nível de comprometimento.

Esses resultados concordam, em parte, com as observações de REYNOLDS e SILVERSTEIN (2003), em que doença articular incidente não foi associada com a dificuldade nas AVDs. No entanto, esses autores verificaram a associação da doença articular prevalente e dificuldade nas AVDs. Essa última associação também foi observada em outros estudos (KLIJS et al., 2001; DUNLOP et al., 2002; LING et al., 2006; TAS et al., 2006; CHAUDHRY et al., 
2010). CHAUDHRY et al. (2010) também observaram associação significativa entre a doença articular e a dificuldade de mobilidade.

Observou-se no modelo sem ajustes a associação significativa entre a doença articular incidente e a dificuldade de mobilidade. Entretanto, após os ajustes por variáveis sociodemográficas essa associação foi perdida. Esses achados do presente estudo podem estar relacionados à baixa frequência da doença articular tanto prevalente $(8,4 \%)$ quanto incidente $(15,2 \%)$ na amostra estudada, frequências essas que se diferem dos estudos anteriormente apresentados, variando entre $23,5 \%$ (REYNOLDS e SILVERSTEIN, 2003) e $57,0 \%$ (SONG et al., 2006).

Entretanto, o risco atribuível da doença articular no comprometimento funcional, de $21,5 \%$, apesar de ter sido menor do que os estudos de DUNLOP et al. (2002) e SONG et al. (2006) - 25,0\% e 23,7\%, respectivamente - essa diferença encontrada não foi contrastante. Ainda, segundo o estudo de GRIFFITH et al. (2010) o risco do comprometimento funcional atribuível à doença articular variou entre 7,9\% e 24,4\%, dependendo do sexo e da idade e da gravidade do comprometimento. Ressalta-se que esse estudo foi transversal e a prevalência da doença articular foi de 56,5\%, considerada alta. Por outro lado, no estudo de KATTAINEN et al. (2004) o risco atribuível de comprometimento funcional foi de $17,4 \%$ entre os homens e $12,0 \%$ entre as mulheres, considerando condições musculoesqueléticas em geral, mesmo com a prevalência dessas condições terem sido elevadas (53,0\%, entre os homens e $62,1 \%$, entre as mulheres). 
Ainda, SOUSA et al. (2009) verificaram um menor risco da incapacidade atribuível à artrite foi de $9,9 \%$, enquanto que a outras doenças foram: à demência ( $25,1 \%)$, ao acidente vascular encefálico $(11,4 \%)$, ao diabete melito $(4,1 \%)$, às doenças respiratórias $(3,3 \%)$ e às doenças cardíacas $(0,8 \%)$.

Entretanto, o risco atribuível populacional à doença articular no comprometimento funcional de $9,2 \%$ na população de idosos do município de São Paulo possa ser considerado baixo frente aos demais resultados. Essa diferença pode ser explicada pela baixa prevalência da doença articular selecionada para esse estudo (23,6\%), utilizada para esses cálculos. Essa prevalência foi baixa, pois ao consideramos apenas os idosos sem qualquer dificuldade funcional, muitos com a doença articular referida não foram incluídos na atual amostra.

No presente estudo, dentre os idosos com comprometimento funcional, em $30,1 \%$ esse comprometimento pode ter sido devido à doença articular. Se houver um controle da doença articular e uma orientação e educação desses pacientes logo nos primeiros sintomas da doença esse processo pode ser reversível ou postergado, podendo evitar $21,5 \%$ da incidência da doença articular nessa população.

Esses resultados, apesar de terem se apresentado discrepantes em relação à literatura, podem estar relacionados à própria história da doença articular e seus comprometimentos, mostrando que o primeiro impacto da doença pode estar relacionado com a mobilidade, posteriormente ocasionando 
comprometimento do desempenho das atividades de vida diária (IDLAND, 2013).

Apesar de não ser possível avaliar se o diagnóstico da doença ocorreu antes ou depois da limitação, é possível que a evolução da degeneração articular tenha comprometido a funcionalidade e levado o idoso procurar assistência médica. Essa hipótese baseia-se no fato da própria história da doença articular que, estando relacionada com a incapacidade não catastrófica, é lenta e progressiva (VERBRUGGE e JETTE, 1994).

É reconhecido na literatura que quando não há incapacidade catastrófica esse processo se inicia com desenvolvimento de dificuldade no desempenho de ações mais ampla, evoluindo para atividades da vida em sociedade e, posteriormente, para as atividades de autocuidado (VERBRUGGE e JETTE, 1994).

Adicionalmente, os resultados encontrados, distintos para o surgimento da doença articular prevalente e incidente, poderiam ser explicado pela influência direta da doença articular e o aparecimento das dificuldades em ações de mobilidade com a busca por assistência à saúde, o que pode ter permitido o diagnóstico. Essa hipótese se baseia no modelo de incapacidade de VERBRUGGE e JETTE (1994), que considera que a dificuldade de mobilidade surge em decorrência da presença de doença.

Ainda, o fato de a dificuldade nas AVDs ter sido mais incidente entre os mais idosos que relataram a doença desde 2000 , poderia estar relacionado ao caráter de limitação progressiva da doença pois, provavelmente para o grupo que referiu a doença articular em 2000, o tempo de exposição à doença pode 
estar associado o processo de incapacitação mais acentuado, a ponto de, em um período de seis anos, já apresentarem incapacidades, o que não ocorreu entre aqueles que referiram a doença em 2000.

Assim, o presente estudo poderia constituir uma estimativa da relação entre a história natural da incapacidade e a doença articular, entretanto, talvez seja necessário um tempo maior de seguimento da coorte.

Além do estudo da associação entre o comprometimento funcional e a doença articular, foi possível observar que o sexo feminino foi associado à dificuldade de mobilidade, enquanto idade a partir de 70 anos e baixo nível de escolaridade foram associados independentemente à dificuldade nas AVDs.

Em relação ao sexo, é reconhecido na literatura o maior comprometimento entre as mulheres (KOUKOULI et al., 2002; ROSA et al., 2003; VON STRAUSS et al., 2003; DUBA et al., 2012), entretanto, no presente estudo, essa associação somente foi observada para a dificuldade de mobilidade não para o desempenho das AVDs. Tais resultados poderiam estar relacionados ao fato de que enquanto o comprometimento funcional das mulheres é de forma lenta e progressiva, entre os homens não, que entre esses pode-se considerar que são mais propensos a não relatarem o comprometimento (FERRUCCI et al., 1996). Outro fator que pode ter influenciado os resultados é o tempo de seguimento para o desenvolvimento da dificuldade em desempenhar as AVDs dado que não havia se desenvolvido também a dificuldade na mobilidade, conforme a hipótese do modelo de incapacidade de VERBRUGGE e JETTE (1994). 
Quanto à idade e o comprometimento funcional, no presente estudo a associação somente foi verificada na faixa etária a partir de 70 anos e apenas entre aqueles com dificuldade em desempenhar AVDs. Os estudos de TAS et al. (2007) e CHAUDHRY et al. (2010) observaram o risco conforme o aumento da idade, sendo que esses útlimos autores observaram o mesmo para a dificuldade de mobilidade. No estudo de SONG et al. (2006) essa associação foi verificada para a faixa etária a partir de 85 anos. Assim, os resultados do presente relacionados ao comprometimento das AVDs podem estar relacionados ao modelo do processo de incapacidade de VERBRUGGE e JETTE (1994), enquanto a dificuldade de mobilidade pode indicar que outros fatores não relacionados à idade são mais comprometedores.

Já o baixo nível de escolaridade, que apresenta associação com o comprometimento funcional em outros estudos (CHAUDHRY et al., 2010; REYNOLDS e SILVERSTEIN, 2003; TAS et al., 2007; LIN et al., 2010) e no presente pode refletir uma pior condição de saúde, dado o baixo nível socioeconômico, de informação e acesso aos serviços de saúde que reflete no acesso aos serviços de saúde curativos e preventivos ao longo da vida, bem como os hábitos de vida mais saudáveis dessa parcela da população. (HARRIS et al., 1989).

Tanto no modelo da OMS (2003) quanto no de VERBRUGGE e JETTE (1994), as condições de saúde são fatores que influenciam no comprometimento funcional. No presente estudo, nenhuma das condições de saúde estudadas foi associada ao comprometimento funcional, independente de seu nível. 
Apesar do declínio funcional ter sido uma variável significativa no modelo explicado do presente estudo, ele não foi associado a nenhum nível de comprometimento, apesar da sua associação em outros estudos (SAUVAGET et al., 2002; REYNOLDS e SILVERSTEIN, 2003; CHAUDHRY et al., 2010; KATTAINEN et al., 2004; DEN OUDEN et al., 2012). Ressalta-se que esse tipo de comprometimento pode limitar o desempenho funcional interferindo nas atividades sociais e rotineiras, como consequência das disfunções de memória, julgamento e reconhecimento (GNJIDIC et al., 2012). No presente estudo, é provável que a baixa prevalência desse sintoma na amostra não tenha permitido detectar associação no modelo multinomial.

Entre os idosos do estudo, mais de um quarto apresentava sobrepeso ou obesidade, apesar disso, a presença de sobrepeso ou obesidade nesse estudo também não apresentou associação estatisticamente significativa com a dificuldade de mobilidade ou nas AVDs, diferentemente do observado em outros estudos.

SONG et al. (2006) encontraram associação entre obesidade e dificuldade em desempenhar as AVDs, assim como o estudo de CHAUDHRY et al. (2010), que encontrou essa associação tanto para incapacidade quanto para limitação funcional. Entretanto, DUNLOP et al. (2002) verificaram que a obesidade não estava associada com a incapacidade.

No estudo de OLDRIGDE e STUMP (2004) a presença de sobrepeso (considerado maior que a média do IMC) mostrou-se associada tanto à limitação quanto à incapacidade funcional, entretanto, na presença de doença 
cardíaca, essa associação perdeu significância (não explicado o motivo pelos autores).

No estudo de TAS et al. (2007) a obesidade entre os homens não foi associada à dificuldade em desempenhar as AVDs grave (3 ou mais atividades), enquanto no estudo de LING et al. (2006) não se mostrou associada à dificuldade de mobilidade de membros inferiores, assim como no estudo de REYNOLDS e SILVERSTEIN (2003).

Apesar de essas inconsistências na literatura, o sobrepeso e a obesidade são fatores importantes a serem considerados no processo de incapacidade dada a sobrecarga que ocasionam nas articulações dos membros inferiores, e ao aumento na propensão dos idosos à ocorrência de quedas sabidamente incapacitantes (HIMES e REYNOLDS, 2012). Tais condições são intensificadas na presença de doença articular, pois o excesso de peso pode aumentar, ainda mais, a sobrecarga nas articulações (HOOTMAN et al., 2012).

Entretanto, em parte, essas inconsistências da literatura podem ser em decorrência das diferentes categorizações utilizadas: variável contínua (REYOLDS e SILVERSTEIN, 2003; TAS et al. 2007), maior do que a média do IMC da amostra estudada (OLDRIGDE e STUMP, 2004) e IMC maior ou igual a 30 a partir de peso e altura autorreferidos (SONG et al., 2006). Outro fator que pode ter influenciado nos resultados e que seria importante ser abordado em futuros estudos longitudinais é a variação do peso entre as ondas.

No que tange às doenças crônicas, associadas ao comprometimento funcional na literatura (ODDING et al., 2001; DUNLOP et al., 2002; COVINSKY et al., 2008; SOUSA et al., 2009; LIN et al. 2011), não observou-se associação 
no presente estudo. Como o foco do presente estudo foi a doença articular, optou-se por controlar as demais doenças como uma única variável. Ainda, o fato da associação entre a doença articular e a limitação articular ter perdido a significância estatística quando se incluiu as doenças crônicas pode estar influenciado pelo fato de considerarmos doença crônica em quantidade e não qualidade da doença, como doenças cardíacas, pulmonares, diabete e acidente vascular encefálico, doenças que comprometem a funcionalidade distintamente.

Os sintomas depressivos, associados ao processo de incapacidade na literatura (CHAUDHRY et al., 2010; SONG et al., 2006) foi excluído do modelo final por não ter sido associado ao comprometimento funcional e por não ter ajustado o modelo, principalmente em decorrência da interferência na ampliação do intervalo de confiança relacionado ao declínio cognitivo. Isso ocorreu porque o número de idosos com sintomas depressivos e dificuldade nas AVDs foi relativamente pequeno quando controlado pelos demais fatores e, para não comprometer as demais análises, optou-se pela exclusão dessa variável. Esse comportamento pode ser, em parte, explicado pelo fato da flutuação do relato desses sintomas.

Independente dos fatores associados ao comprometimento funcional, é importante considerar que o relato de dificuldades funcionais pode se constituir como um importante marcador clínico para a identificação mais precoce de doença articular e adoção de medidas que posterguem ou evitem o declínio funcional. No estudo de GUCCIONE et al. (1994), a proporção de dificuldade de mobilidade atribuída à osteoartrose de joelho foi de $16,7 \%$ para subir um 
lance de escada, 15,4\% para caminhar um quarteirão e 16,6\% para carregar peso. Foram as proporções mais altas em relação às demais comorbidades e condições de saúde, reiterando o papel da doença articular nessas atividades.

Entretanto, no presente estudo, quando estratificado por sexo e faixa etária, observa-se entre os idosos com a doença incidente que os homens em geral e os idosos mais novos (independente do sexo) (entre 60 e 69 anos) possuem maior risco em apresentar a dificuldade na ação de ajoelhar-se ou agachar-se. Esses resultados corroboram com o perfil da doença, que acomete os homens principalmente a articulação do joelho (ISSA e SHARMA, 2006). Quando observado entre as mulheres, a doença relatada desde 2000 apresenta risco maior para a dificuldade em estender os braços acima dos ombros, dificuldade essa também entre os idosos mais novos, de ambos os sexos.

Ajoelhar envolve tanto a força de quadríceps quanto a amplitude de movimento da articulação femoropatelar e tibiofemoral (RUNHAAR et al., 2011), enquanto a ação de estender os braços acima dos ombros envolve principalmente a articulação glenoumeral e acromioclavicular, com suas bursas, tendões e espaço intrarticular (FAYAD et al., 2008). A doença articular pode levar à diminuição do espaço intrarticular e aumento de atrito na articulação pela formação dos osteófitos (MCDONOUGH e JETTE, 2010).

Consequentemente, essas alterações fisiológicas podem levar à dificuldade nas ações que envolvem essas articulações, comprometendo assim a amplitude de movimento. Tal comprometimento pode evoluir para a fuga do movimento, pela dor e pela compensação do movimento e, assim, levar ao 
desuso. Com isso, outras ações e atividades que envolvem a amplitude de movimentos dessas articulações podem vir a serem comprometidas. Assim, é plausível que esse comprometimento articular afete inicialmente as ações de mobilidade, principalmente as que envolvem as articulações femoropaletar e glenoumeral (MCDONOUGH e JETTE, 2010).

A dificuldade de mobilidade pode levar ao desenvolvimento da dificuldade em desempenhar as AVDs (IDLAND, 2013). Dessa forma, a manutenção da força dos grandes grupos musculares de membros inferiores e superiores e da amplitude de movimento e o controle da dor são orientações de promoção da saúde que tendem a ser fundamentais para a prevenção do comprometimento funcional (SURI et al., 2012).

O comprometimento funcional dos idosos é e será um problema de massa que tem recebido assistência inadequada tanto familiar quando individual, diante dessa magnitude que necessita de uma resposta social (EBRAHIM, 1999). Orientações à família para estimular a autonomia e independência do idoso ou o auxílio nas atividades podem postergar o declínio funcional ao longo do tempo.

Tratamentos que não demandam grandes tecnologias e eficazes estão disponíveis para o controle da progressão da doença articular, como atividade física para manutenção da força de quadríceps - com caminhadas, por exemplo -, exercícios aeróbicos para condicionamento físico e manutenção da flexibilidade (SBR, 2003), além da a recomendação de perda de peso para não sobrecarregar as articulações, principalmente as dos membros inferiores e 
injeção de ácido hialurônico, que mantém a lubrificação do espaço intra articular (SBR, 2003; EDMONDS, 2009).

Além disso, tratamentos fisioterapêuticos específicos, como treinamento de força, estimulação elétrica, terapia manual e de equilíbrio são técnicas reconhecidas com boa resposta ao tratamento pelos pacientes, conforme revisão de BRAKKE et al. (2012).

Independente dos fatores associados, na população do município de São Paulo, de cada 100 idosos que desenvolveram limitação funcional, nove poderiam ser evitadas se a doença articular fosse eliminada na população.

Adicionalmente, considerando que o comprometimento funcional associado à doença articular é lento, se houver a detecção precoce desse comprometimento ainda no início, enquanto limita apenas ações, como levantar os braços ou flexionar os joelhos, pode surtir bons resultados e pouco impacto no orçamento, com orientações sobre a importância da atividade física para pessoas com essa doença e quais os tipos de atividades recomendadas para elas e estimular essa prática (HOOTMAN et al., 2002).

Dessa forma, se considerarmos que em 2020 a população paulistana terá $1.963 .047^{2}$ idosos e que o cenário de hoje não se alterará, 176.674 idosos poderão não ter comprometimento funcional se houverem ações de saúde pública voltadas para o controle da doença articular. Com medidas simples de orientação aos familiares e cuidadores para que a força muscular e amplitude do movimento da articulação sejam mantidas e um acompanhamento rotineiro no serviço de saúde para as assistências médica, farmacêutica e

\footnotetext{
${ }^{2}$ Dados disponibilizados pela Fundação SEADE (http://www.seade.gov.br/produtos/projpop/)
} 
fisioterapêutica necessárias, o comprometimento funcional pode ser controlado, evitando ou retardando o aparecimento das dificuldades na mobilidade e, consequentemente no desempenho das AVDs futuras desses idosos para e na sociedade.

Portanto, esse impacto que a doença articular pode causar no comprometimento funcional dos idosos a longo prazo, se detectado no início, intervenções mais simples e menos onerosas e para um público menor poderão ser mais efetivas e eficazes.

\subsection{Limitações e Perspectivas}

Apesar das doenças crônicas terem sido auto-referidas e, assim, uma media aproximada das informações obtidas em exames e consultas clínicas, a concordância quando comparada a registros médicos é boa (THEME FILHA, SZWARCWALD e SOUZA JUNIOR, 2008).

O critério de seleção para inclusão da população de estudo (sem comprometimento funcional) pode ter enviesado a amostra com um perfil mais saudável, com a proporção de idosos doentes em menor proporção do que a amostra inicial da coorte. Isso pode, em parte, justificar o fato de o período de acompanhamento de 6 anos ter sido considerado curto frente a uma população com um perfil diferenciado.

Nesse estudo optou-se por estudar a transição do relato apenas da doença articular, entretanto, em futuros estudos a transição do relato entre uma 
onda e outra de outras variáveis estudadas pode vir a acrescentar uma informação diferencial.

Uma outra possibilidade de estudo para evitar o viés de seleção da amostra e ser mais fidedigno ao perfil da população seria avaliar o declínio funcional. Entretanto, para tal, seria também necessário que as escalas de avaliação fossem mais consolidadas e seus padrões de comportamento entre coortes permitissem a seleção das atividades-chave para acompanhamento. 


\section{CONCLUSÃO}

$\mathrm{Na}$ população de idosos do município de São Paulo, 9,2\% do comprometimento funcional pode ser atribuído à doença articular.

Para um período de 6 anos, 47,8\% dessa população desenvolveu dificuldade de mobilidade e 7,3\% dificuldade em desempenhar as AVDs.

As atividades de mobilidade que envolvem membros inferiores foram associadas à doença articular incidente, enquanto as atividades que envolvem os membros superiores foram associadas à doença articular prevalente.

A doença articular não foi associada ao comprometimento funcional, sendo que este foi associado ao sexo feminino para a dificuldade de mobilidade e a dificuldade em desempenhar as AVDs foi associada à idade mais avançada e à baixa escolaridade.

Conclui-se que se a doença pudesse ser prevenida, o risco do comprometimento funcional cairia para $21,5 \%$. Ainda, entre os idosos que relataram a doença articular $30,1 \%$ do comprometimento funcional são atribuídos à doença. 


\section{REFERÊNCIAS BIBLIOGRÁFICAS}

Al Snih SA, Markides KS, Ray L, Goodwin JS. Impact of pain on disability among older mexican americans. J Gerontol A Biol Sci Med Sci. $2001 ; 56(7): M 400-4$.

Alexandre TDS, Corona, LP, Nunes DP, Santos JLF, Duarte YAO, Lebrão ML. Gender differences in incidence and determinants of disability in activities of daily living among elderly individuals: SABE study. Arch Gerontol Geriatr. 2012;55(2):431-37.

Alves LC, Leimann BCQ, Vasconcelos MEL, Carvalho MS, Vasconcelos AGG, Fonseca TCO et al. A influência das doenças crônicas na capacidade funcional dos idosos do Município de São Paulo, Brasil. Cad. Saúde Pública. 2007;23(8):1924-30.

Anderson G, Horvarth J. The growing burden of chronic disease in America. Public Health Rep. 2004;119(3):263-70.

Balzi D, Lauretani F, Barchielli A, Ferrucci L, Bandinelli S, Buiatti E, et al. Risk factors for disability in older persons over 3-year follow-up. Age Ageing. 2010;39(1):92-8.

Bielak AAM, Byles JE, Luszcz MA, Anstey KJ. Combining longitudinal studies showed prevalence of disease differed throughout older adulthood. J Clin Epidemiol. 2012;65 (3):317-24.

Bindawas SM, Al Snih S, Grady JJ, Protas, EJ Graham JE, Markides KS et al. Evidence of reduced health-related quality of life in older Mexican Americans with arthritis. Ethn Dis. 2011;21(2):230-6.

Bos SD, Slagboom PE, Meulenbelt I. New insights into osteoarthritis: early developmental features of an ageing-related disease. Curr Opin Rheumatol. 2008;20 (5):553-9.

Brakke R, Singh J, Sullivan W. Physical therapy in persons with osteoarthritis. PM and R. 2012; 4(5 SUPPL.):S53-S58.

Brito, F. Transição demográfica e desigualdades sociais no Brasil. Rev Bras Estud Popul. 2008;25(1):5-26.

Busija L, Hollingsworth B, Buchbinder R, Osborne RH. Role of age, sex, and obesity in the higher prevalence of arthritis among lower socioeconomic groups: a population-based survey. Arthritis Rheum. 2007;57(4):553-61. 
Camargos MCS, Perpetuo IHO, Machado CJ. Expectativa de vida com incapacidade funcional em idosos em São Paulo, Brasil. Rev Panam Salud Publica. 2005;17:5-6.

Carvalho JAM, Rodriguez-Wong LL. A transição da estrutura etária da população brasileira na primeira metade do século XXI. Cad Saúde Pública. 2008;24(3):597-605.

Chaudhry SI, Mcavay G, Ning Y, Allore HG, Newman AB, Gill TM. Geriatric impairments and disability: the cardiovascular health study. J Am Geriatr Soc. 2010;58(9):1686-92.

Cho HJ, Chang CB, Kim KW, Park JH, Yoo JH, Koh IJ, et al. Gender and prevalence of knee osteoarthritis types in elderly Koreans. J Arthroplasty. $2011 ; 26(7): 994-9$.

Chopra A, Abdel-Nasser A. Epidemiology of rheumatic musculoskeletal disorders in the developing world. Best Pract Res Clin Rheumatol. 2008;22(4):583-604.

Covinsky KE, Lindquist K, Dunlop DD, Gill TM, Yelin E. Effect of arthritis in middle age on older-age functioning. J Am Geriatr Soc. 2008;56(1):23-8.

Covinsky KE. Aging, Arthritis, and Disability. Arthritis Rheum. 2006;55(2):175-6.

Den Ouden MEM, Schuurmans MJ, Arts IEMA, Van Der Schouw YT. Physical performance characteristics related to disability in older persons: a systematic review. Maturitas. 2011;69(3):208-19.

Duba AS, Rajkumar AP, Prince M, Jacob KS. Determinants of disability among the elderly population in a rural south indian community: The need to study local issues and contexts. Int Psychogeriatr. 2012;24(2):333-41.

Dunlop DD, Hughes SL, Manheim LM. Disability in activities of daily living: patterns of change and a hierarchy of disability. Am J Public Health. 1997;87(3):378-83.

Dunlop DD, Manheim LM, Song J, Chang RW. Arthritis prevalence and activity limitations in older adults. Arthritis Rheum. 2001;44(1):212-21.

Dunlop DD, Manheim LM, Sohn M, Liu X, Chang RW. Incidence of functional limitation in older adults: The impact of gender, race, and chronic conditions. Arch Phys Med Rehabil. 2002;83(7):964-71.

Ebrahim SLancet. Disability in older people: a mass problem requiring mass solutions. 1999;353(9169):1990-2.

Edmonds S. Therapeutic targets for osteoarthritis. Maturitas. 2009;63(3):191-4. 
Fayad F, Roby-Bramib a, Yazbeckc C, Hannetonb S, Lefevre-Colaua MM, Gautherond V et al. Three-dimensional scapular kinematics and scapulohumeral rhythm in patients with glenohumeral osteoarthritis or frozen shoulder. J Biomechanics. 2008;41:326-332.

Felson DT, Lawrence RC, Dieppe PA, Hirsch R, Helmick CG, Jordan JM et al. Osteoarthritis: new insights - part 1: the disease and its risk factors. Ann Intern Med 2000. 133(8):635-46.

Felson DT, Nevitt MC. Epidemiologic studies for osteoarthritis: new versus conventional study design approaches. Rheum Dis Clin North Am. 2004;30(4):783-97.

Ferrucci L, Guralnik JM, Simonsick E, Salive ME, Corti C, Langlois J. Progressive versus catastrophic disability: a longitudinal view of the disablement process. J Gerontol A Biol Sci Med Sci. 1996;51(3):M123-30.

Fisher MN, Al Snih S, Ostir GV, Goodwin JS. Positive affect and disability among older mexican americans with arthritis. Arthritis Care Res. 2004;51(1):34-9.

Folstein MF, Folstein SE, McHugh PR. "Mini-mental state". A practical method for grading the cognitive state of patients for the clinician. $J$ Psychiatr Res. 1975;12(3):189-98.

Fonda S, Herzog AR. Documentation of physical functioning measured in the Health and Retirement Study and the asset and health dynamics among the oldest old study. Ann Arbor; 2004 [acesso em 20 de novembro de 2012]. Disponível em: http://hrsonline.isr.umich.edu/sitedocs/userg/dr-008.pdf

Freedman VA, Martin LG. Contribution of chronic conditions to aggregate changes in old-age functioning. Am J Public Health 2000;90(11):1755-60.

Fried LP, Bandeen-Roche K, Chaves PHM, Johnson BA. Preclinical mobility disability predicts incident mobility disability in older women. Journals of Gerontology - Series A Biological Sciences and Medical Sciences 2000;55(1):M43-52.

Fried LP, Bandeen-Roche K, Kasper JD, Guralnik JM. Association of comorbidity with disability in older women: the women's health and aging study. J Clin Epidemiol. 1999;52(1):27-37.

Fried LP, Ferrucci L, Darer J, Williamson JD, Anderson G. Untangling the concepts of disability, frailty, and comorbidity: Implications for improved targeting and care. J Gerontol A Biol Sci Med Sci. 2004;59(3):255-63. 
Gill TM, Allore HG, Holford TR, Guo Z. Hospitalization, restricted activity, and the development of disability among older persons. J Am Med Assoc. $2004 ; 292(17): 2115-24$.

Gill TM, Robison JT, Tinetti ME. Difficulty and dependence: two components of the disability continuum among community-living older persons. Ann Intern Med. 1998;128(2):96-101.

Gnjidic D, Stanaway FF, Cumming R, Waite L, Blyth F, Naganathan et al. Mild cognitive impairment predicts institutionalization among older men: a population-based cohort study. PLoS One. 2012;7(9):e46061.

Graciani A, Banegas JR, López-García E, Rodríguez-Artalejo F. Prevalence of disability and associated social and health-related factors among the elderly in spain: a population-based study. Maturitas. 2004;48(4):381-92.

Griffith L, Raina P, Wu H, Zhu B, Stathokostas L. Population attributable risk for functional disability associated with chronic conditions in canadian older adults. Age Ageing. 2010;39(6):738-45.

Guccione AA, Felson DT, Anderson JJ, Anthony JM, Zhang Y, Wilson PWF et al. The effects of specific medical conditions on the functional limitations of elders in the Framingham Study. Am J Public Health. 1994;84(3):351-8.

Guccione AA, Felson DT, Anderson JJ. Defining arthritis and measuring functional status in elders: methodological issues in the study of disease and physical disability. Am J Public Health. 1990;80(8):945-9.

Guillemin F, Rat AC, Mazieres B, Pouchot J, Fautrel B, Euller-Ziegler L et al. Prevalence of symptomatic hip and knee osteoarthritis: a two-phase populationbased survey. Osteoarthr Cartil. 2011;19(11):1314-22.

Guralnik JM, Fried LP, Salive ME. Disability as a public health outcome in the aging population. Annu Rev Public Health. 1996;17:25-46.

Hamerman D. Clinical implications of osteoarthritis and ageing. Ann Rheum Dis. $1995 ; 54(2): 82-5$.

Harris T, Kovar MG, Suzman R, Kleinman JC, Feldman JJ. Longitudinal study of physical ability in the oldest-old. Am J Public Health. 1989;79(6):698-702.

Himes CL, Reynolds SL. Effect of obesity on falls, injury, and disability. J Am Geriatr Soc. 2012;60(1):124-9.

Hootman JM, Helmick CG, Brady TJ. A public health approach to addressing arthritis in older adults: The most common cause of disability. Am J Public Health. 2012;102(3):426-33. 
Hootman JM, Helmick CG. Projections of US prevalence of arthritis and associated activity limitations. Arthritis Rheum. 2006;54(1):226-9.

Hootman JM, Sniezek JE, Helmick CG. Women and arthritis: burden, impact, and prevention programs. Journal of Women's Health.2002;11(5):407-16.

Horváth G, Koroknai G, Ács B, Than P, Bellyei A, Illés T. Prevalence of radiographic primary hip and knee osteoarthritis in a representative central european population. Int Orthop. 2011;35(7):971-5.

IBGE - Instituto Brasileiro de Geografia e Estatística. Projeção da População do Brasil por Sexo e Idade 1980-2050. Revisão 2008. Rio de Janeiro; 2010.

IBGE - Instituto Brasileiro de Geografia e Estatística. Sinopse do Censo demográfico. Rio de Janeiro; 2011.

IBGE - Instituto Brasileiro de Geografia e Estatística. Um Panorama da Saúde no Brasil - Acesso e utilização dos serviços, condições de saúde e fatores de risco e proteção à saúde 2008. Rio de Janeiro; 2010.

Idland G, Pettersen R, Avlund K, Bergland A. Physical performance as longterm predictor of onset of activities of daily living (ADL) disability: A 9-year longitudinal study among community-dwelling older women. Arch Gerontol Geriatr. In press. 2013.

Issa SN, Sharma L. Epidemiology of osteoarthritis: an update. Curr Rheumatol Rep. 2006;8(1):7-15.

Kattainen A, Koskinen S, Reunanen A, Martelin T, Knekt P, Aromaa A. Impact of cardiovascular diseases on activity limitations and need for help among older persons. J Clin Epidemiol. 2004;57(1):82-8.

Katz S, Ford AB, Moskowitz RW, Jackson BA, Jaffe MW. Studies of illness in the aged. The index of ADL: a standardized measure of biological and psychosocial function. JAMA. 1963;185(12):914-9.

Klijs B, Nusselder WJ, Looman CW, Mackenbach JP. Contribution of chronic disease to the burden of disability. PLoS ONE. 2011;6(9).

Kopec JA, Rahman MM, Berthelot J-M, Le Petit C, Aghajanian J, Sayre EC, et al. Descriptive epidemiology of osteoarthritis in British Columbia, Canada. J Rheumatol. 2007;34:386-93.

Koukouli S, Vlachonikolis IG, Philalithis A. Socio-demographic factors and selfreported functional status: The significance of social support. BMC Health Services Research. 2002;2(1):20.

Kwok WY, Vliet Vlieland TPM, Rosendaal FR, Huizinga TWJ, Kloppenburg M. Limitations in daily activities are the major determinant of reduced health-related 
quality of life in patients with hand osteoarthritis. Ann Rheum Dis. $2011 ; 70(2): 334-6$.

Lawton MP, Brody EM. Assessment of older people: Self-maintaining and instrumental activities of daily living. Gerontologist. 1969;9(3):179-86.

Lebrão ML, Duarte YAO. O Projeto SABE no município de São Paulo: uma abordagem inicial: OPAS; 2003.

Lin K-, Chen $\mathrm{P}$, Twisk JWR, Lee $\mathrm{H}$, Chi L. Time-varying nature of risk factors for the longitudinal development of disability in older adults with arthritis. Journal of Epidemiology. 2010;20(6):460-7.

Ling SM, Xue QL, Simonsick EM, Tian J, Bandeen-Roche K, Fried LP et al. Transitions to mobility difficulty associated with lower extremity osteoarthritis in high functioning older women: longitudinal data from the women's health and aging study II. Arthritis Care Res. 2006;55(2):256-63.

Liu J, Chi I, Chen G, Song X, Zheng X. Prevalence and correlates of functional disability in chinese older adults. Geriatrics and Gerontology International 2009;9(3):253-61.

Machado GPM, Barreto S M, Passos VMA, Lima-Costa MFF. Projeto Bambuí: prevalência de sintomas articulares crônicos em idosos. Rev Assoc Med Bras. 2004;50(4):367-72.

Majer IM, Nusselder WJ, Mackenbach JP, Klijs B, Van Baal PHM. Mortality risk associated with disability: a population-based record linkage study. Am J Public Health. 2011;101(12):e9-e15.

Malta DC, Cezário AC, Moura L, Morais NOL, Silva Junior JB. A construção da vigilância e prevenção das doenças crônicas não transmissíveis no contexto do Sistema Único de Saúde. Epidemiol. Serv. Saúde. 2006;15(3):47-65.

March LM, Bagga R. Epidemiology of osteoarthritis in Australia. Med J Aust. 2004;180(5 Suppl):S6-S10.

McDonough CM, Jette AM. The contribution of osteoarthritis to functional limitations and disability. Clin Geriatr Med. 2010;26(3):387-99.

Mendes ACG, Sá DA, Miranda GMD, Lyra TM, Tavares RAW. Assistência pública de saúde no contexto da transição demográfica brasileira: exigências atuais e futuras. Cad. Saúde Pública. 2012;28(5):955-64.

Mendes, EV. O cuidado das condições crônicas na atenção primária à saúde: 0 imperativo da consolidação da estratégia da saúde da família. Brasília: Organização Pan-Americana da Saúde. 2012. 
MS - Ministério da Saúde. Secretaria de Atenção à Saúde. Departamento de Atenção Básica. Envelhecimento e saúde da pessoa idosa. Cadernos de Atenção Básica, n. 19. Brasília-DF, 2007.

National Institute of Aging. National Institutes of Health, US Dept. of Health \& Human Services, US Dept. of State. Why Population Aging Matters: A Global Perspective. Washington DC: National Institute of Aging, 2007.

Nagi SZ. An epidemiology of disability among adults in the United States. Milbank Memorial Fund Quarterly: Human and Society. 1976;54:439-467.

Nishimura A, Hasegawa M, Kato K, Yamada T, Uchida A, Sudo A. Risk factors for the incidence and progression of radiographic osteoarthritis of the knee among Japanese. Int Orthop. 2011;35(6):839-43.

O'Brien RM. A caution regarding rules of thumb for variance inflation factors. Qual Quant. 2007;41:673-690.

Odding E, Valkenburg HA, Algra D, Vandenouweland FA, Grobbee DE, Hofman A. Associations of radiological osteoarthritis of the hip and knee with locomotor disability in the rotterdam study. Ann Rheum Dis. 1998;57(4):203-8.

Odding E, Valkenburg HA, Stam HJ, Hofman A. Determinants of locomotor disability in people aged 55 years and over: The Rotterdam study. Eur J Epidemiol. 2001;17(11):1033-41.

Oldridge NB, Stump TE. Heart disease, comorbidity, and activity limitation in community-dwelling elderly. Eur J Prev Cardiol. 2004;11(5):427-34.

Oman D, Reed D, Ferrara A. Do elderly women have more physical disability than men do? Am J Epidemiol. 1999;150(8):834-42.

OMS - Organização Mundial de Saúde. Organização Panamericana de Saúde (OPAS). Classificação estatística internacional de doenças e problemas relacionados à saúde: CID-10. São Paulo, 1995.

OMS - Organização Mundial de Saúde. Organização Panamericana de Saúde (OPAS). Cuidados inovadores para condições crônicas: componentes estruturais de ação: relatório mundial. Brasília, 2003.

OMS - Organização Mundial de Saúde. Organização Panamericana de Saúde (OPAS). CIF - Classificação internacional de funcionalidade, incapacidade e saúde. São Paulo, 2003.

OPAS - Organização Panamericana de Saúde. World Health Organization; Brasil. Ministério da Saúde. Secretaria de Vigilância em Saúde. Envelhecimento ativo: uma política de saúde. Brasília-DF, 2005. 
Paes-Sousa R. Diferenciais intra-urbanos de mortalidade em Belo Horizonte, Minas Gerais, Brasil, 1994: revisitando o debate sobre transições demográfica e epidemiológica. Cad. Saúde Pública. 2002;18(5):1411-21.

Palacios-Ceña D, Jiménez-García R, Hernández-Barrera V, Alonso-Blanco C, Carrasco-Garrido P, Fernández-de-las-Peñas $C$. Has the prevalence of disability increased over the past decade (2000-2007) in elderly people? J Am Med Dir Assoc. 2012;13(2):136-42.

Palazzo C, Ravaud JF, Trinquart L, Dalichampt M, Ravaud P, Poiraudeau S. Respective contribution of chronic conditions to disability in france: results from the national disability-health survey. PLoS One. 2012;7(9):e44994.

Parahyba MI, Simões CCS. A prevalência de incapacidade funcional em idosos no Brasil. Ciênc. Saúde Coletiva. 2006;11(4):967-74.

Paschoal SMP. Qualidade de vida do idoso: construção de um instrumento de avaliação através do método do impacto clínico [tese]. São Paulo: , Faculdade de Medicina; 2004

Peláez-Ballestas I, Sanin LH, Moreno-Montoya J, Alvarez-Nemegyei J, BurgosVargas R, Garza-Elizondo $M$ et al. Epidemiology of the rheumatic diseases in Mexico: a study of 5 regions based on the COPCORD methodology. J Rheumatol. 2011;38(SUPPL. 86):3-6.

Pueyo MJ, Surís X, Larrosa M, Auleda J, Mompart A, Brugulat $P$ et al. Importance of chronic musculoskeletal problems in the population of Catalonia (Spain): prevalence and effect on self-perceived health, activity restriction and use of health services. Gac Sanit. 2012;26(1):30-6.

Rasch EK, Hirsch R, Paulose-Ram R, Hochberg MC. Prevalence of rheumatoid arthritis in persons 60 years of age and older in the United States: effect of different methods of case classification. Arthritis Rheum. 2003;48(4):917-26.

Reynolds SL, Silverstein M. Observing the onset of disability in older adults. Soc Sci Med. 2003;57(10):1875-89.

Rosa TEC, Benício MHD, Latorre MRDO, Ramos LR. Fatores determinantes da capacidade funcional entre idosos. Rev. Saúde Pública. 2003;37(1):40-48.

Rosow L, Breslau N. A Guttman health scale for the aged. Gerontology. 1966;21:556-559.

Runhaar J, Koes BW, Clockaerts S, Bierma-Zeinstra SMA. A systematic review on changed biomechanics of lower extremities in obese individuals: a possible role in development of osteoarthritis. Ob Review. 2011;12:1071-1082. 
Saad PM, Miller T, Martinez C. Impacto de los cambios demográficos en las demandas sectoriales en América Latina. R. bras. Est. Pop. 2009;26(2): 237261.

Samper-Ternent R, Kuo YF, Ray LA, Ottenbacher KJ, Markides KS, Al Snih S. Prevalence of health conditions and predictors of mortality in oldest old mexican americans and non-hispanic whites. J Am Med Dir Assoc. 2012;13(3):254-9.

Sauvaget, C., Yamada, M., Fujiwara, S., Sasaki, H., Mimori, Y et al. Dementia as a predictor of functional disability: a four-year follow-up study. Gerontology. 2002;48(4):226-233.

SBR - Sociedade Brasileira de Reumatologia. Projeto Diretrizes. Osteoartrite (artrose): tratamento. Rio de Janeiro; 2003. [acesso em 20 de novembro de 2012]. Disponível em: http://www.projetodiretrizes.org.br/projeto_diretrizes/077.pdf.

Schramm JMA, Oliveira AF, Leite IC, Valente JG, Gadelha AMJ, Portela MC et al . Transição epidemiológica e o estudo de carga de doença no Brasil. Ciênc. Saúde Coletiva. 2004;9(4):897-908.

Scott WK, Macera CA, Cornman CB, Sharpe PA. Functional health status as a predictor of mortality in men and women over 65. J Clin Epidemiol. 1997;50(3):291-6.

Silva NM. Aspectos metodológicos: processo de amostragem. In: Lebrão ML, Duarte YAO. SABE: Saúde, Bem-estar e Envelhecimento - O projeto SABE no município de São Paulo: uma abordagem inicial. Brasília: OPAS; 2003.

Smith S, Heffler S, Freeland M. The impact of technological change on health care cost spending: An evaluation of the literature. Health Care Financing Administration; 2000. [acesso em 20 de janeiro de 2012). Disponível em: http://www.cms.gov/Research-Statistics-Data-and-Systems/Statistics-Trendsand-Reports/NationalHealthExpendData/downloads/tech_2000_0810.pdf.

Song J, Chang RW, Dunlop DD. Population impact of arthritis on disability in older adults. Arthritis Care Res. 2006;55(2):248-55.

Sousa M, Ferri CP, Acosta D, Albanese E, Guerra M, Huang Y et al. Contribution of chronic diseases to disability in elderly people in countries with low and middle incomes: a 10/66 dementia research group population-based survey. Lancet. 2009;374(9704):1821-30.

Stanton MW, Rutherford MK. The high concentration of U.S. health care expenditures. Research in Action. AHRQ Pub; 2006. [acesso em 20 de novembro de 2012]. Disponível em: http://www.ahrq.gov/research/ria19/expendria.pdf. 
Stedman, TL. Stedman dicionário médico. Rio de Janeiro: Guanabara Koogan; 2003.

Suri P, Morgenroth DC, Hunter DJ. Epidemiology of osteoarthritis and associated comorbidities. PM and R. 2012;4(5 SUPPL.):S10-9.

Tas Ü, Verhagen AP, Bierma-Zeinstra SMA, Hofman A, Odding E, Pols HAP, Koes BW. Incidence and risk factors of disability in the elderly: the Rotterdam study. Prev Med. 2007;44(3):272-8.

Theme Filha MM, Szwarcwald CL, Souza Junior PRB. Medidas de morbidade referida e inter-relações com dimensões de saúde. Rev. Saúde Pública. 2008; 42(1):73-81.

Verbrugge LM, Jette AM. The disablement process. Soc Sci Med. 1994;38(1):114.

Von Strauss E, Agüero-Torres H, Kåreholt I, Winblad B, Fratiglioni L. Women are more disabled in basic activities of daily living than men only in very advanced ages: a study on disability, morbidity, and mortality from the Kungsholmen project. J Clin Epidemiol. 2003;56(7):669-77.

WHO. World Health Organ Tech Rep Ser. The burden of musculoskeletal conditions at the start of the new millennium. 2003;919:i-x, 1-218.

Woo J, Ho SC, Yu ALM, Lau J. An estimate of long-term care needs and identification of risk factors for institutionalization among Hong Kong chinese aged 70 years and over. J Gerontol A Biol Sci Med Sci. 2000;55(2):M64-9.

Zhang Y, Jordan JM. Epidemiology of osteoarthritis. Clin Geriatr Med. 2010;26(3):355-69.

Zhao G, Ford ES, Li C, Crews JE, Mokdad AH. Disability and its correlates with chronic morbidities among U.S. adults aged 50-<65 years. Prev Med. 2009;48(2):117-21. 


\section{ANEXOS}

Anexo 1 - Questionários SABE

2000: Disponível em: http://www.fsp.usp.br/sabe/Extras/Questionario 2000.pdf 2006: Disponível em: http://www.fsp.usp.br/sabe/Extras/Questionario 2006.pdf 


\section{Anexo 2 - Pareceres do Comitê de Ética em Pesquisa}

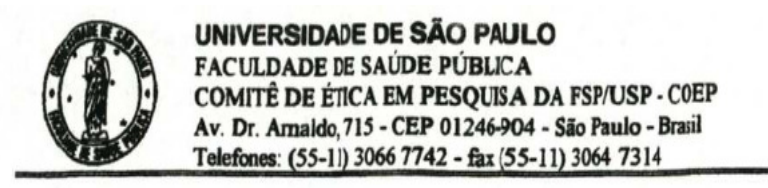

Of.COEP/67/99

24 de maio de 1999

Pelo presente, informo que o Comitê de Ética em Pesquisa, aprovou, em sua 3.199, Sessão Ordinária, de 19.05.99, de acordo com os requisitos da Resolução CNS/196/96, o Projeto de Pesquisa "AS CONDIÇ̃̃ES DE SAÚDE DOS IDOSOS NA AMÉRICA DO SUL E CARIBE", apresentado pelo pesquisador Ruy Laurenti, devendo ser remetido à CONEP conforme as normas da Resolução 196/96.

Atenciosamente,

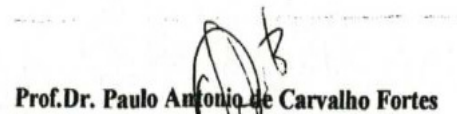

Vice-Coordenador do Comitê fe Éfity em Pesquisa da FSP-COEP 


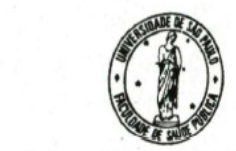

Universidade de São Paulo

Faculdade de Saúde Pública

COMITÊ DE ÉTICA - COEP

Av. Dr. Arnalț, 715 - Assessıria Acalcêmica - CEP 01246-904 - Sãos Paulo - Brasil

Telefones: (55-11) 3066-7779 - e-mail: corpp(ufsp.usp.hr

\section{Of.COEP/83/06}

14 de março de 2006

Pelo presente, informo que o Comitê de Ética em Pesquisa da Faculdade de Saúde Pública da Universidade de São Paulo-COEP, aprovou o Protocolo de Pesquisa n. ${ }^{\circ}$ 1345, intitulado: "PROJETO SABE-2005 - SAÚDE, BEM-ESTAR E ENVELHECIMENTO. AS CONDIÇÕES DE SAÚdE E DE VIDA DOS IDOSOS NO MUNICÍPIO DE SÃO PAULO", apresentado pela pesquisadora Maria Lúcia Lebrăo.

Atenciosamente,

$$
\begin{gathered}
\text { Welma the Sada Jatumabr } \\
\text { Heleng Akemi Wada Watanabe } \\
\text { Professora Doutora }
\end{gathered}
$$

Vice-Coordenadora do Comitê de Ética em Pesquisa da FSP-COEP 


\section{CURRÍCULO LATTES}

\section{Francine Leite}

Endereço para acessar este CV: http://lattes.cnpq.br/5442378334683594

Última atualização do currículo em 07/01/2013

Formada em Fisioterapia pela Universidade Estadual de São Paulo. Ganhadora do prêmio Jovem Pesquisador do Simpósio Internacional e Brasileiro de Dor em 2005. Defendeu a dissertação de Mestrado sobre "Influência da restrição do crescimento intra-uterino na idade da menarca", em 2009, pelo Faculdade de Medicina de Ribeirão Preto da Universidade de São Paulo (FMRP/USP). Trabalha como pesquisadora no Instituto de Estudos de Saúde Suplementar (IESS). Atualmente, é aluna de doutorado pela USP no curso de Pós-Graduação em Saúde Pública, na área de concentração em Epidemiologia, tendo como orientadora a Prof. ${ }^{a}$. Dr. ${ }^{a}$ Yeda Aparecida de Oliveira Duarte.(Texto informado pelo autor)

\section{Identificação}

$\begin{array}{ll}\text { Nome } & \text { Francine Leite } \\ \text { Nome em citações bibliográficas } & \text { LEITE, Francine } \\ \text { Sexo } & \text { Feminino }\end{array}$

\section{Endereço}

\section{Endereço Profissional}

Instituto de Estudos de Saúde Suplementar.

Rua Joaquim Floriano, 1052 cj42

Itaim Bibi

04534-004 - Sao Paulo, SP - Brasil

Telefone: (11) 37069744

URL da Homepage: www.iess.org.br

\section{Formação acadêmica/titulação}

\section{9}

Doutorado em andamento em Saúde Pública (Conceito CAPES 5).

Universidade de São Paulo, USP, Brasil.

Título: Impacto da doença articular referida na funcionalidade de idosos,

Orientador: Yeda Aparecida de Oliveira Duarte.

Palavras-chave: epidemiologia; doença articular; idosos.

Grande área: Ciências da Saúde / Área: Saúde Coletiva / Subárea: Saúde Pública.

Grande Área: Ciências da Saúde / Área: Saúde Coletiva / Subárea: Epidemiologia.

2007 - 2009

Mestrado em Saúde na Comunidade (Conceito CAPES 5).

Universidade de São Paulo, USP, Brasil.

Título: Influência da restrição do crescimento intra-uterino na idade da menarca: estudo da coorte de nascidos vivos de Ribeirão Preto de 1978/9,Ano de Obtenção: 2009.

Orientador: Maria da Conceição Pereira Saraiva.

Bolsista do(a): Coordenação de Aperfeiçoamento de Pessoal de Nível Superior.

Palavras-chave: epidemiologia.

Grande área: Ciências da Saúde / Área: Saúde Coletiva.

Grande Área: Ciências da Saúde / Área: Saúde Coletiva / Subárea: Epidemiologia.

Grande Área: Ciências Exatas e da Terra / Área: Probabilidade e Estatística / Subárea: Estatística / Especialidade: Análise de

Dados.

$2002-2005$

Graduação em Fisioterapia.

Universidade Estadual Paulista Júlio de Mesquita Filho, UNESP, Brasil.

Título: Estudo epidemiológico da dor crônica no ambulatório de Fisioterapia da FCT-UNESP, Campus de Presidente Prudente".

Orientador: Jaime de Oliveira Gomes. 


\section{Yeda Aparecida de Oliveira Duarte}

Bolsista de Produtividade em Pesquisa do CNPq - Nível 2

Endereço para acessar este CV: http://lattes.cnpq.br/4648711010185688

Última atualização do currículo em 11/10/2012

Graduada em Enfermagem pela Escola de Enfermagem da USP (1982), mestrado (1996) e doutorado (2001) em Enfermagem pela Universidade de São Paulo - área:Gerontologia. Pós Doutorado em Epidemiologia pela Faculdade de Saúde Pública da USP com estágio no Sealy Center on Aging - University of Texas Medical Brunch (2005). Atualmente é Professora Associada da Universidade de São Paulo. É pesquisadora do Estudo SABE - Saúde, Bem estar e Envelhecimento, estudo longitudinal sobre as condições de vida e saúde dos idosos residentes no Municipio de São Paulo. Coordenou o Estudo longitudinal sobre os determinantes de fragilidade em pessoas idosas em velhice avançada. Foi responsável pela criação do primeiro Curso de Graduação em Gerontologia sediado na Universidade de São Paulo. É co-lider do Grupo de pesquisa "Saúde Pública e Envelhecimento". Tem experiência na área de Enfermagem, com ênfase em Geriatria e Gerontologia, atuando principalmente nos seguintes temas: idosos, assistência domiciliária, estudo sabe, envelhecimento e gerontologia. (Texto informado pelo autor)

\section{Identificação}

$\begin{array}{ll}\text { Nome } & \text { Yeda Aparecida de Oliveira Duarte } \\ \text { Nome em citações bibliográficas } & \text { DUARTE, Y. A. O.; de Oliveira Duarte, Y. A.;Duarte, Y.;Duarte, Yeda Aparecida } \\ \text { Oliveira } & \end{array}$

Sexo

Feminino

\section{Endereço}

\section{Endereço Profissional}

Universidade de São Paulo, Escola de Enfermagem, Departamento de Enfermagem Médico-Cirúrgica.

Avenida Dr. Enéas de Carvalho Aguiar, 419 - 3o. andar - Sala 318

Cerqueira Cesar

05403-000 - Sao Paulo, SP - Brasil

Telefone: (11) 30617544

Ramal: 7500

Fax: (11) 30617546

URL da Homepage: http://www.ee.usp.br

\section{Formação acadêmica/titulação}

\section{5}

Livre-docência.

Escola de Enfermagem da Usp.

Título: Envelhecimento, funcionalidade e arranjos domiciliares na América Latina e Caribe, Ano de obtenção: 2005.

Palavras-chave: envelhecimento; funcionalidade; arranjos domiciliares; Estudo SABE.

Grande área: Ciências da Saúde / Área: Saúde Coletiva / Subárea: Gerontologia / Especialidade: Gerontologia.

Grande Área: Ciências da Saúde / Área: Saúde Coletiva / Subárea: Epidemiologia / Especialidade: Gerontologia.

Setores de atividade: Políticas, Planejamento e Gestão em Saúde; Cuidado À Saúde das Populações Humanas.

$2004-2005$

Pós-Doutorado.

Faculdade de Saúde Pública da Usp.

Grande área: Ciências da Saúde / Área: Saúde Coletiva / Subárea: Saúde Pública / Especialidade: Gerontologia.

Grande Área: Ciências da Saúde / Área: Enfermagem / Subárea: Enfermagem de Saúde Pública / Especialidade: Epidemiologia. 1997 - 2001

Doutorado em Enfermagem (Conceito CAPES 5).

Universidade de São Paulo, USP, Brasil.

Título: Família: recurso terapêutico ou fator estressor. A ótica de idosos e cuidadores familiares"., Ano de obtenção: 2001.

Orientador: Tamara Iwanow Cianciarullo.

Palavras-chave: família; idosos; cuidadores; Avaliação de Famílias; Rede de suporte Social.

Grande área: Ciências da Saúde / Área: Enfermagem / Subárea: Enfermagem Médico-Cirúrgica.

Grande Área: Ciências da Saúde / Área: Enfermagem / Subárea: Enfermagem Médico-Cirúrgica / Especialidade: Geriatria e Gerontologia.

Grande Área: Ciências da Saúde / Área: Enfermagem / Subárea: Enfermagem Médico-Cirúrgica / Especialidade: Assistência Domiciliária.

Setores de atividade: Saúde Humana. 